\title{
Permeability Estimation Directly From Logging-While-Drilling Induced Polarization Data
}

Fiandaca, G.; Maurya, P.K.; Balbarini, Nicola; Hördt, A.; Christiansen, A.V.; Foged, N.; Bjerg, Poul Løgstrup; Auken, E.

Published in:

Water Resources Research

Link to article, DOI:

10.1002/2017WR022411

Publication date:

2018

Document Version

Peer reviewed version

Link back to DTU Orbit

Citation (APA):

Fiandaca, G., Maurya, P. K., Balbarini, N., Hördt, A., Christiansen, A. V., Foged, N., Bjerg, P. L., \& Auken, E. (2018). Permeability Estimation Directly From Logging-While-Drilling Induced Polarization Data. Water Resources Research, 54(4), 2851-2870. https://doi.org/10.1002/2017WR022411

\section{General rights}

Copyright and moral rights for the publications made accessible in the public portal are retained by the authors and/or other copyright owners and it is a condition of accessing publications that users recognise and abide by the legal requirements associated with these rights.

- Users may download and print one copy of any publication from the public portal for the purpose of private study or research.

- You may not further distribute the material or use it for any profit-making activity or commercial gain

- You may freely distribute the URL identifying the publication in the public portal 


\section{Permeability estimation directly from logging-while-drilling Induced}

\section{Polarization data}

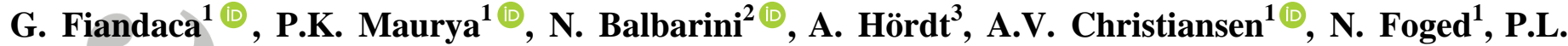

\section{Bjerg $^{2}{ }^{(\mathbb{D}}$, and E. Auken ${ }^{1}(\mathbb{D}$}

${ }^{1}$ HydroGeophysics Group, Department of Geoscience, Aarhus University, C.F. Møllers Alle 4, 8000, Aarhus C, Denmark.

2 Technical University of Denmark, Department of Environmental Engineering, Bygningstorvet, building 115, 2800 Kgs. Lyngby, Denmark.

${ }^{3}$ Institute for Geophysik und extraterrestrische Physik, TU Braunschweig, Mendelssohnstr. 3, 38106 Braunschweig, Germany.

Corresponding author: Gianluca Fiandaca (gianluca.fiandaca@geo.au.dk)

\section{Key Points:}

- Permeability prediction from time-domain spectral induced polarization data measured in the undisturbed formation using El-log technique

- Laboratory-derived empirical equations for unconsolidated sediments were used, without any further calibration

- IP-derived permeability within one decade from GSA and slug test estimates, with weak effect of electrical water conductivity

This article has been accepted for publication and undergone full peer review but has not been through the copyediting, typesetting, pagination and proofreading process which may lead to differences between this version and the Version of Record. Please cite this article as an 'Accepted Article', doi: 10.1002/2017WR 022411 


\begin{abstract}
In this study we present the prediction of permeability from time-domain spectral induced polarization (IP) data, measured in boreholes on undisturbed formations using the El-log loggingwhile-drilling technique. We collected El-log data and hydraulic properties on unconsolidated Quaternary and Miocene deposits in boreholes at three locations at a field site in Denmark, characterized by different electrical water conductivity and chemistry. The high vertical resolution of the El-log technique matches the lithological variability at the site, minimizing ambiguity in the interpretation originating from resolution issues. The permeability values were computed from IP data using a laboratory-derived empirical relationship presented in a recent study for saturated unconsolidated sediments, without any further calibration. A very good correlation, within one order of magnitude, was found between the IP-derived permeability estimates and those derived using grain size analyses and slug-tests, with similar depth-trends and permeability contrasts. Furthermore, the effect of water conductivity on the IP-derived permeability estimations was found negligible in comparison to the permeability uncertainties estimated from the inversion and the laboratory-derived empirical relationship.
\end{abstract}

\title{
1. Introduction
}

The permeability $(k)$, or its counterpart hydraulic conductivity, is a key parameter in hydrogeological investigations as it is a main requirement for groundwater flow characterization within an aquifer. Traditionally, the spatial distribution of $k$ is estimated by grain-size analyses of samples from drillings or with in-situ slug-tests in screened boreholes. These methods are expensive, time consuming and sometimes unreliable [Rosas et al., 2014]. For example, grain size analysis (GSA) requires good quality of soil or sediment samples which does not necessarily represent the aquifer heterogeneity and can be disrupted or washed out during the drilling process. Moreover it is based on some empirical equations which have their own limitations [Rosas et al., 
2014]. In comparison to GSA, Slug test (ST) measurements are more reliable, but they are still local measurements and are prone to wellbore skin effects [Hinsby et al., 1992].

As an alternative approach, geophysical methods have been increasingly used for permeability mapping, and spectral induced polarization (SIP) has indicated its potential in permeability estimation in the laboratory [e.g., A. Binley et al., 2005; Börner et al., 1996; Revil and Florsch, 2010; Slater, 2007; Andreas Weller et al., 2015a; Zisser et al., 2010].

SIP is a geophysical technique used to measure the diffusion-controlled polarization processes at the interface between mineral grains and the pore fluid. The IP response is usually represented as complex conductivity, $\sigma^{*}=\left(\sigma_{\text {bulk }}+\sigma_{\text {surf }}^{\prime}\right)+i \sigma_{\text {surf }}^{\prime \prime}$, where $\sigma_{\text {bulk }}$ is the bulk conduction through the pore volume, $\sigma_{\text {surf }}^{\prime}$ represents the surface conduction along the mineral-fluid interface and the imaginary part $\sigma_{\text {surf }}^{\prime \prime}$ is related to the polarization of the charges at this interface $[L D$ Slater and $D$ Lesmes, 2002]. The imaginary part $\sigma_{\text {surf }}^{\prime \prime}$ (hereafter referred to as $\sigma^{\prime \prime}$ ) is commonly used to represent the magnitude of the interfacial polarization.

Models describing the relationships between polarization response and permeability can be categorized in two classes. The first class is based on $\sigma^{\prime \prime}$ and the second class is based on relaxation time, a quantity used to represent the characteristic hydraulic length scale [Revil, 2012]. The relaxation time can be extracted for instance by Debye-Decomposition [Nordsiek and Weller, 2008] or from Cole-Cole inversion [Florsch et al., 2014] of complex conductivity spectra. In our study the $\sigma^{\prime \prime}$-based approach was used. The premise of estimating $k$ using $\sigma^{\prime \prime}$ is based on its strong relationship with surface area normalized to the pore volume $\left(S_{\text {por }}\right)$, which holds the fundamental basis for derived empirical relationships between $k$ and $\sigma^{\prime \prime}$ in laboratory studies [Börner et al., 1996; L Slater and D P Lesmes, 2002; Andreas Weller et al., 2015a].

Despite the potential shown by the IP method for estimating permeability in the laboratory, the effectiveness of the method at field scale has yet to be extensively evaluated. Three main issues are 
reoccurring in the few attempts published so far: 1) the lack of spatial resolution in the geophysical imaging at the scale of the field variability [e.g. Attwa and Günther, 2013; Andrew Binley et al., 2016; A. Hördt et al., 2009; P. K. Maurya et al., 2018]; 2) the use of site-specific relations between IP properties and permeability [e.g. Attwa and Günther, 2013; Börner et al., 1996; Andreas Hördt et al., 2007; Kemna et al., 2004]; 3) the use of relations between IP properties and permeability derived for lithologies different from the ones present in the field [e.g. A. Hördt et al., 2009; A Weller and Börner, 1996].

The aim of this work is to evaluate the capability of the IP method in predicting permeability at field scale, in presence of heterogeneity in both lithology and water chemistry, overcoming the above-mentioned limitations. Firstly, the SIP data were acquired in-situ through the El-log drilling technique [Sфrensen and Larsen, 1999] extended to time-domain (TD) SIP measurements [Gazoty et al., 2012]. The technique measures TD SIP data while drilling, through electrodes embedded in the stem auger. No drilling mud or borehole back-filling are used, allowing for measurements on "undisturbed" formations. Hence, the high vertical resolution of the El-log technique allows for ruling out a limited spatial resolution from the possible ambiguities in the interpretation of the IPderived $k$ estimates. Secondly, permeability was estimated using the $\sigma^{\prime \prime}$-based approach of Andreas Weller et al. [2015a] for unconsolidated materials, derived from an extensive dataset of laboratory data, without any further site-specific calibration. Permeability estimations from small-scale borehole measurements (down to $5 \mathrm{~m}$ ) are presented also in Weller and Börner [1996] and Börner et al. [1996] but, as previously stated, the relation between IP properties and permeability was calibrated in Börner et al. [1996], while in Weller and Börner [1996] relations derived for lithologies different from the ones present in the field were used (and the correlation between IPderived permeability and the grain size analysis was not optimal).

The El-log TD SIP data were collected in three locations in an unconsolidated aquifer with Quaternary and Miocene deposits in the Grindsted area in the south-western part of Denmark 
(Figure 1). The aquifer south of the stream is contaminated by a leachate plume from the former Grindsted landfill, and significant variations in electrical water conductivity and inorganic water chemistry are present among the three El-logs (water conductivity: here and throughout the manuscript conductivity always refers to electrical water conductivity). Consequently, the effect of water conductivity/chemistry on the quality of the IP-derived k estimates is studied.

The decays were carefully processed and inverted using the inversion algorithm by G. Fiandaca et al. [2012], that supports the modelling of full-decay and waveform. The IP-derived permeability values were compared to an extensive set of independent permeability estimates, composed by 54 GSA estimates on sediment samples and 9 ST measurements. Finally, the surface area per unit volume, $\mathrm{S}_{\text {por, }}$ was measured on 25 samples with the BET method [Brunauer et al., 1938] and compared to the IP-derived values.

\section{Material and methods}

\subsection{Study area}

The study was carried out in an aquifer near the Grindsted landfill situated in an outwash plain west of the main stationary line of the Weichselian glaciation (Figure 1). The upper Quaternary sediments in the aquifer consists mainly of medium to coarse meltwater sand [Heron et al., 1998] , while the underlying Miocene sediments are primarily medium to fine mica-rich sand with interbedded thin clay and lignite layers [Heron et al., 1998]. The water table is located 1-3 m below the terrain. The hydraulic gradient shows an overall westerly flow direction towards the Grindsted stream (Figure 1). The Grindsted landfill has historical deposits of municipal solid waste, industrial waste, sewage treatment waste, and demolition waste [Peter Kjeldsen et al., 1998]. There is no liner or leachate collection beneath the landfill.

El-log E1 is situated south of the landfill (Figure 1) and expected to be unaffected by the landfill leachate plume [Bjerg et al., 1995]. El-log E2 is placed in the core of the landfill leachate plume in 
an area highly contaminated with organic and inorganic contaminants (see Table S1 in supplementary information). This is also reflected in a recent mapping of the plume by using 2D and 3D electrical resistivity tomography [Pradip Kumar Maurya et al., 2017]. El-log E3 is placed in similar deposits north of the Grindsted stream as shown in Figure 1. Each El-log has a corresponding borehole (Bh1-Bh3) drilled for lithological description and collection of water samples, and a sediment core ( $\mathrm{Sc} 1)$ was collected next to E1 as well. The permeability estimation from IP data has an underlying assumption for its applicability in contaminated sites: the contamination should have neither IP nor DC signature, except for the effect of water conductivity. This requirement is not always fulfilled, for instance in subsurface settings contaminated with NAPLs [Chen et al., 2012; Johansson et al., 2015; e.g., Adrian Flores Orozco et al., 2011; A.F. Orozco et al., 2012]. However, the IP signature is usually significant only where the contaminants are present in concentrations close to the saturation point (e.g. above $1 \mathrm{~g} / \mathrm{l}$ for BTEX in A.F. Orozco et al. [2012]). At the stream site the concentrations are much below this concentration level [P. K. Maurya et al., 2018] and will not have any influence on IP or DC signature. At the landfill site there is no presence of NAPL in the plume. The landfill is in the methanogenic phase $[P$. Kjeldsen et al., 1998] and the organic matter/dissolved organic carbon is expected to be dominated by fully dissolved humic like compounds without effect on EC and IP signals [Christensen et al., 2001].

\subsection{El-log technique}

The El-log is a high resolution drilling technique used in groundwater and environmental investigations for unconsolidated sediments. The El-log technique provides "while-drilling" measurements of the direct current (DC) resistivity, TD SIP decays and gamma radiation [Gazoty et al., 2012; Sørensen and Larsen, 1999]. Apparent resistivity and chargeability are measured using the electrodes integrated in the hollow stem auger (Figure 2). The electrodes are embedded in insulating material and the gamma probe is located close to the drilling head. Gamma probe and 
electrodes are connected to a control unit on the surface through the cables passing in the hollow stem auger. The control unit receives the signal from gamma probe and sends the data to a field PC and passes the electrode connection to the multi-channel resistivity meter. A Pole-Pole configuration is used for measurements with two potential and one current electrodes in the auger (spaced $0.2 \mathrm{~m}$ ). Two electrodes are placed on the surface as remote potential and current electrodes and are connected to the control unit. Measurements can be performed while the drill stem is rotating if good electrode contact is maintained. Alternatively, the drill rotation is paused briefly at regular depth intervals to obtain measurements. In addition to the logging equipment, a water sampler device is also located inside the auger, with inlets close to the drill tip, and is connected through the tubes to the surface.

\subsection{Acquisition, processing and inversion of El-log TD SIP data}

For recording of TD SIP data, we used the Terrameter-LS instrument (ABEM) and full-waveform data were recorded at a sampling rate of $3750 \mathrm{~Hz}$. In borehole E2 and E3 a 4 second on-time and 4 second off-time cycle was used whereas a 2 second on- and off-time was used in E1. A 50\% duty cycle (50\% on-time and 50\% off-time) waveform was used in E2 and E3, while both 50\% duty cycle and $100 \%$ duty cycle (no off-time) waveforms [P I Olsson et al., 2015] were measured in E1 (except $5 \mathrm{~m}$ data from depth 16 to $21 \mathrm{~m}$, measured only with $100 \%$ duty cycle because of an instrumental failure that prevented the acquisition of the $50 \%$ duty cycle data). The acquisition parameters in the boreholes are slightly different from each other, because the loggings in E2 and E3 were originally not done with the purpose of estimating permeability. Only after the potential had been recognized, the data in E2 and E3 were analyzed for permeability estimation. The conclusions will not be affected by the differences in the acquisition settings, because the current waveform is taken into account in the forward algorithm and the permeability estimation will be based on well resolved inversion parameters. In any case, for minimizing the differences in the analyses of the three boreholes, the $50 \%$ duty cycle data were used for E1, where possible. 
A maximum current of $200 \mathrm{~mA}$ was used. The resistivity and IP decay data were measured while the auger was moving and rotating.

The full-waveform data were processed for harmonic de-noising and removal of background potential drift following P-I Olsson et al. [2016]. These processed data were then gated using 33 logarithmically spaced tapered time windows in the interval $1 \mathrm{~ms}-3980 \mathrm{~ms}$ (gate widths starting at $0.26 \mathrm{~ms}$, ending at $820 \mathrm{~ms}$ ) for the 4 second pulses and in the interval $1 \mathrm{~ms}-1980 \mathrm{~ms}$ (gate width $0.26 \mathrm{~ms}$ to $420 \mathrm{~ms}$ ) for the 2 second pulses. The data were then imported to the Aarhus Workbench software (www.aarhusgeosoftware.dk) for further manual editing and processing. In the manual processing, each individual IP decay curve was inspected and noisy data points, for example due to electrode contact problems, were removed. Generally, the first usable gate was found to be around 2-3 ms and the average number of gates was found to be around 30, equivalent of about 3 decades of spectral content.

The inversion of El-log TD SIP data was performed using the AarhusInv [Auken et al., 2014] code, an integrated modeling and inversion code for electrical and electromagnetic data. Forward modeling of El-log TD SIP data follows the recursive formulation by Sato [2000] and takes into account the transmitter waveform and the receiver transfer function [G. Fiandaca et al., 2012].

In the model space, the frequency-dependent complex conductivity $\sigma^{*}$ is described through a reparameterization of the Cole-Cole model, namely the bulk and (maximum) imaginary conductivity (BIC) Cole-Cole model, developed explicitly for being used in permeability estimation and described in details in the next section. Considering the $0.2 \mathrm{~m}$ spacing between the current and potential electrodes in the auger, a $0.2 \mathrm{~m}$ vertical discretization was used in the E-log inversion models.

\subsection{Parameterization of induced polarization}

The Cole-Cole model in its conductivity form is expressed as [e.g. Tarasov and Titov, 2013]: 
$\sigma^{*}(f)=\sigma_{0}\left[1+\frac{m_{0}}{1-m_{0}}\left(1-\frac{1}{1+\left(i 2 \pi f \tau_{\sigma}\right)^{C}}\right)\right]$

where $\sigma^{*}$ is the complex conductivity, $\sigma_{0}$ is the DC conductivity, $m_{0}$ is the intrinsic chargeability, $\tau_{\sigma}$ is the relaxation time, $C$ is the frequency exponent, $f$ is the frequency and $i$ is the imaginary unit. In equation (1), the $m_{0}$ and $C$ parameters are strongly correlated, and thus poorly resolved in the inversion [G. Fiandaca et al., 2017; G. Fiandaca et al., 2018]. In order to reduce the parameter correlation, and hence improve the inversion results, Fiandaca et al. [2017a, 2017b] introduced the maximum imaginary conductivity (MIC) model, in which $m_{0}$ is replaced by maximum imaginary conductivity $\sigma_{\max }^{\prime \prime}$ of the Cole-Cole spectrum (Figure 3) and the model space $\boldsymbol{m}_{\boldsymbol{M I C}}$ becomes:

$\boldsymbol{m}_{M I C}=\left\{\sigma_{0}, \sigma_{\max }^{\prime \prime}, \tau_{\sigma}, C\right\}$

In equation (2) $\sigma_{0}$ is the DC conductivity, which is the sum of the bulk conductivity $\sigma_{b u l k}$ and the DC surface conductivity $\sigma_{\text {surf }}^{\prime}(f=0)$ [A. Weller and Boerner, 1996]:

$\sigma_{0}=\sigma_{\text {bulk }}+\sigma_{\text {surf }}^{\prime}(f=0)=\frac{\sigma_{W}}{F}+\sigma_{\text {surf }}^{\prime}(f=0)$

where in the last term of the equality $\sigma_{\text {bulk }}$ is expressed through the formation factor $F$ and the water conductivity $\sigma_{W}$, following Archie's law [Archie, 1942]. When imaging the DC conductivity (or, equivalently, DC resistivity), as in the MIC model, the bulk and surface conduction are not discriminated.

To overcome this limitation the BIC model has been developed, in which we make use of the petrophysical relation between the real and imaginary components of the surface conductivity described in A. Weller et al. [2013]:

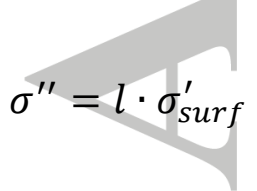

with $l=0.042 \pm 0.022$ (dimension less). The relation in equation (4) was obtained from a database of 63 samples of sandstone and unconsolidated sediments, covering nine independent 
investigations, using multisalinity resistivity measurements and $\sigma^{\prime \prime}$ measurements at a frequency $f \cong 1 \mathrm{~Hz}$. The variability of the proportionality with frequency is not discussed in Weller et al. [2013]; considering that the (surface) imaginary conductivity of the Cole-Cole model reaches a maximum $\sigma_{\text {max }}^{\prime \prime}$ at the frequency $f=1 / 2 \pi \tau_{\sigma}$, we decided to enforce in the BIC model the proportionality between the real and imaginary surface conductivity at this frequency (which is not necessarily $1 \mathrm{~Hz})$ :

$$
\sigma^{\prime \prime}\left(f=1 / 2 \pi \tau_{\sigma}\right)=\sigma_{\max }^{\prime \prime}=l \cdot \sigma_{\text {surf }}^{\prime}\left(f=1 / 2 \pi \tau_{\sigma}\right)
$$

This is a conservative choice: in this way the ratio between the surface imaginary conductivity and real conductivity never exceeds the factor of equation (4). On the contrary, enforcing the proportionality at $f=1 \mathrm{~Hz}$ would imply a ratio well above $l$ at the peak frequency $f=1 / 2 \pi \tau_{\sigma}$ for models with $\tau_{\sigma} \gg 1$.

Enforcing the relation of equation (5) in the MIC Cole-Cole model, it is possible to define the BIC model with model space $\boldsymbol{m}_{\boldsymbol{B} I \boldsymbol{C}}$ defined in terms of the bulk conductivity $\sigma_{\text {bulk }}$, the maximum imaginary conductivity $\sigma_{\max }^{\prime \prime}$ and the other two classic Cole-Cole parameters $\tau_{\sigma}$ and $C$ :

$$
\boldsymbol{m}_{\text {BIC }}=\left\{\sigma_{\text {bulk }}, \sigma_{\text {max }}^{\prime \prime}, \tau_{\sigma}, C\right\}
$$

Therefore, contrary to the MIC model, with the BIC parameterization the bulk conductivity is separated from the DC surface conductivity. This allows for the estimation of the formation factor $F$ directly from the inversion parameters, when the water conductivity is known.

For any given set of parameters of the BIC model it is possible to derive the corresponding ColeCole parameters through simple algebraic relations, and to compute the complex conductivity at any frequency through equation (1). Figure 3 shows the spectrum of the BIC model defined by the parameter values $\left\{\sigma_{\text {bulk }}=10 \mathrm{mS} / \mathrm{m}, \sigma_{\text {max }}^{\prime \prime}=0.1 \mathrm{mS} / \mathrm{m}, \tau_{\sigma}=0.1 \mathrm{~s}, C=0.5\right\}$. The $\sigma_{0}$ and $m_{0}$ 
values of the corresponding Cole-Cole model are $\sigma_{0}=12.1 \mathrm{mS} / \mathrm{m}$ and $m_{0}=38.2 \mathrm{mV} / \mathrm{V}$, respectively.

\subsection{Estimation of permeability and $S_{\text {por }}$}

\subsubsection{Permeability from grain size analysis and slug tests}

Traditional $63 \mathrm{~mm}$ wells (Bh1-Bh3) were installed next to each El-log (E1-E3) using cable tool bailer drilling. Samples were collected every $0.5 \mathrm{~m}$ for geological characterization and grain size analyses. Each well has multiple 1 meter long screens for collecting water samples and performing slug tests. Note that the vertical discretization of the traditional wells is coarser than the $0.2 \mathrm{~m}$ vertical discretization of the El-log retrieved models. In addition, sediment cores (Sc1) were collected in PVC liners by the GeoProbe sampling system close to El-log E1. The cores were split in half for detailed geological characterization and subsampled for laboratory analysis.

Grain size analysis (GSA) was performed on selected soil samples from the cores (Sc1 next to E1) and sampling from drilling of the traditional boreholes (Bh2 and $\mathrm{Bh} 3$ ) using sieving, for particle size between 2 and $0.063 \mathrm{~mm}$, and laser diffractometer (Mastersizer Hydro 2000SM), for particle size between 63 and $0.02 \mu \mathrm{m}$ [Switzer and Pile, 2015]. The grain size distribution curve was used to estimate the permeability. Many approaches have been suggested for this purpose and the calculated permeability can change orders of magnitudes between the various approaches [Devlin, 2015]. Thus, several methods were applied on each sample, depending on the properties of the sample, and the permeability values and their uncertainty were computed through the geometric mean and the standard deviation of the different estimations of the applicable methods. The methods used for the GSA permeability estimations were selected from the review by Devlin [2015] and are: Hazen simplified, [Hazen, 1892], Slichter [Slichter, 1899], Terzaghi [Terzaghi, 1925], Beyer [Beyer, 1964], Sauerbrei [Vuković and Soro, 1992] , Krüger [Krüger, 1918] , Kozeny-Carman [Kozeny, 1953], Zunker [Zunker, 1930], United States Bureau of Reclamation [Białas, 1966], Barr [Barr, 
2001], Alyamani and Sen [Alyamani and Şen, 1993], Chapuis [Chapuis, 2004], and Krumbein and Monk [Krumbein and Monk, 1943]. Not all samples qualify for all methods, and thus the number of methods to calculate the average varies between 2 and 13. On average, the standard deviation of all methods on all sample is 0.3 decades (Table S2 in supplementary material), indicating that the choice of the qualified methods is not crucial and the proposed approach should give robust estimates of permeability values and standard deviations. Table S3 in supplementary documents presents the permeability estimates for all the GSA methods adopted in this study.

Slug tests were performed with a vacuum method developed for measuring local permeability in an unconfined sandy aquifer [Hinsby et al., 1992]. The method consists of raising the water table by using a vacuum pump and monitoring the decrease in water table over time with a 1 second time interval. The groundwater table falling curve was analyzed in AQTESOLV using Bouwer and Rice's method for partially penetrating wells in unconfined aquifers [Bouwer and Rice, 1976], Hvorslev [1951] for partially penetrating wells in confined aquifer, and Springer and Gelhar [1991] when oscillatory responses were observed in the slug test. Two slug tests were performed at each screen and the value of permeability used for comparison was calculated by averaging the result of the two tests. In all cases they agreed well. Values of slug-tests are provided in Table S4 in supplementary material.

\subsubsection{Surface area per unit volume $\left(S_{\text {por }}\right)$ estimates with BET}

The specific surface area was measured on the selected samples from the sediment core (Sc1) using the Brunauer, Emmett, and Teller (BET) gas adsorption method [Brunauer et al., 1938; Santamarina et al., 2002]. The surface area was measured on a dry sample using $\mathrm{N}_{2}$ gas (Micromeritics FlowPrep 060). Since the method required a dry sample, the surface area of interlayer surfaces in swelling clays is only partially measured by the method [Santamarina et al., 2002]. Values of $\boldsymbol{S}_{\text {por }}$ are provided in Table S5 in supplementary material. 


\subsubsection{Permeability and $S_{\text {por }}$ from Spectral IP}

Most of the early works for estimating the permeability $(k)$ were based on a Kozeny-Carman type equation given as:

$k=\frac{\phi}{a S_{\text {por }}^{2}}$

where $\phi$ is the porosity, $\mathrm{T}$ is a pore capillary tortuosity factor, and $a$ is a shape factor. Considering the sensitivity of induced polarization to $S_{p o r}$, a number of efforts have been made to reformulate the equation (7) for more direct use with SIP modeling [Slater, 2007]. For example the ratio $T / \phi$ can be replaced by formation factor $F\left(=T_{e l} / \phi\right)$, assuming that electrical tortuosity $\left(T_{e l}\right)$ is equal to hydraulic tortuosity (T). Such a type of model was proposed by Börner et al. [1996]:

$k=\frac{b}{F S_{p o r}^{c}}$

where $\mathrm{b}$ and $\mathrm{c}$ are empirical constants and $F$ is the formation factor. The two unknowns, $F$ and $S_{\text {por }}$, can be estimated using the SIP measurements. Recently, Andreas Weller et al. [2015a] investigated a data base consisting of 114 globally collected samples. They avoided the indirect $k$-estimation through $S_{\text {por }}$ and suggested direct correlations between $k$ and the imaginary conductivity $\sigma^{\prime \prime}$, measured with a $\mathrm{NaCl}$ solution with standardized electrical conductivity $\sigma_{f}=100 \mathrm{mS} / \mathrm{m}$ at a frequency $f \cong 1 \mathrm{~Hz}$. For unconsolidated (saturated) sediments they proposed two empirical equations:

$k=\frac{1.08 \cdot 10^{-13}}{F^{1.12} \cdot\left(\sigma^{\prime \prime}\left(\sigma_{f}\right)\right)^{2.27}}$

$k=3.47 \cdot 10^{-16} \cdot \frac{\left(\sigma_{0}\left(\sigma_{f}\right)\right)^{1.11}}{\left(\sigma^{\prime \prime}\left(\sigma_{f}\right)\right)^{2.41}}$

where $k$ is given in $\mathrm{m}^{2}, \sigma_{0}$ and $\sigma^{\prime \prime}$ are given in $\mathrm{mS} / \mathrm{m}$ and $F$ is dimension less. Equation (9), likewise equation (8), depends on the formation factor $F$, while equation (10) depends on the DC 
conductivity $\sigma_{0}$. The assumption in equation (10) is that the apparent formation factor $F^{\prime}=\frac{\sigma_{f}}{\sigma_{0}\left(\sigma_{f}\right)}$ can be used in permeability estimation instead of the true formation factor $F$, which is rarely available for most practical field applications in hydrogeophysics. This assumption was found valid by Andreas Weller et al. [2015a] for unconsolidated samples, while for consolidated samples the prediction based on $F$ was superior (because the exponents of $F$ and $\sigma_{0}$ in the formula equivalent to equations (9) and (10) are higher for consolidated samples, and the formation factor plays a bigger role in the permeability estimation).

Although the explicit calculation of $S_{\text {por }}$ is no longer necessary to estimate $k$ from equations (9) and (10), $S_{\text {por }}$ is still a macroscopic parameter that can be measured in the laboratory and the relation between $\sigma^{\prime \prime}$ and $S_{\text {por }}$ is the theoretical basis of the permeability estimation. Therefore, we also estimate $S_{\text {por }}$ using the following relationship with $\sigma^{\prime \prime}$ :

$$
\sigma^{\prime \prime}=C_{p} S_{p o r}
$$

where $C_{p}$ is called the specific polarizability [A. Weller et al., 2010].

\subsubsection{Permeability estimation from inversion parameters and effect of water conductivity}

The empirical equations (9) and (10) link the permeability, which is a function of the material structure only, to the electrical properties of the material, which depend also on the electrical water conductivity and, for the surface properties, also on the water chemistry. This is why the equations are derived from a standardized water solution (i.e. $\mathrm{NaCl}$ solution with electrical conductivity $\sigma_{f}=100 \mathrm{mS} / \mathrm{m}$ ). In field surveys, the water solution can be assumed to be known, but its conductivity will generally not equal $100 \frac{\mathrm{ms}}{\mathrm{m}}$ nor the solute will be only $\mathrm{NaCl}$.

The dependency of the imaginary surface conductivity on the water solution for consolidated and unconsolidated sediments can be expressed as [A. Weller and Slater, 2012; A. Weller et al., 2011; Andreas Weller et al., 2015a]: 


$$
\sigma^{\prime \prime}\left(\sigma_{w}\right)=\sigma^{\prime \prime}\left(\sigma_{f}\right) \cdot \frac{1}{C_{f}} \cdot\left(\frac{\sigma_{w}}{\sigma_{f}}\right)^{a}
$$

where $\sigma_{f}=100 \mathrm{mS} / \mathrm{m}$ represents the electrical conductivity of a reference $\mathrm{NaCl}$ solution, $C_{f}$ accounts for the possible differences in ionic species between the reference and actual solution and the exponent $a$ depends on the material. Weller et al. [2011] found $a=0.5$ for sandstones, and Weller et al. [2015a] used $a=0.5$ for both sandstones and unconsolidated samples in the correction for water conductivity in permeability estimations. Nevertheless, Weller and Slater [2012] showed a certain variability in the exponent $a$ for the correction on unconsolidated samples, with average value and standard deviation equal to $a=0.37 \pm 0.12$ (these estimates are not shown explicitly in Weller and Slater [2012], but can be retrieved from the full set of values shown in table 1 therein).

In order to use equation (9) from the inversions of field data, as we do in this study, the formation factor and the imaginary surface conductivity $\sigma^{\prime \prime}$ (for standardized solution at frequency $f=1 \mathrm{~Hz}$ ) need to be estimated. Remember that through the BIC model as defined through equations (3-6), we obtain the bulk electrical conductivity, which does not include surface conductivity any more. We can thus calculate the formation factor directly from $F=\frac{\sigma_{W}}{\sigma_{\text {bulk }}}$.

Using equation (12) with $a=0.37$ and calculating the formation factor as explained above, we obtain:

$$
\begin{aligned}
& F^{1.12} \cdot\left(\sigma^{\prime \prime}\left(\sigma_{f}\right)\right)^{2.27}= \\
& =\left(\frac{\sigma_{w}}{\sigma_{\text {bulk }}}\right)^{1.12} \cdot\left(\sigma^{\prime \prime}\left(\sigma_{w}\right) \cdot C_{f} \cdot\left(\frac{\sigma_{f}}{\sigma_{w}}\right)^{0.37}\right)^{2.27}=C_{f}^{2.27} \cdot \sigma_{f}^{0.84} \cdot \frac{\left(\sigma^{\prime \prime}\left(\sigma_{w}\right)\right)^{2.27}}{\left(\sigma_{\text {bulk }}\left(\sigma_{w}\right)\right)^{1.12}} \cdot \sigma_{w}{ }^{0.28}= \\
& =4.78 \cdot 10^{1} \cdot C_{f}{ }^{2.27} \cdot \frac{\left(\sigma^{\prime \prime}\left(\sigma_{w}\right)\right)^{2.27}}{\left(\sigma_{\text {bulk }}\left(\sigma_{w}\right)\right)^{1.12}} \cdot \sigma_{w}{ }^{0.28}
\end{aligned}
$$


where in the last equality $\sigma_{f}=100 \mathrm{mS} / \mathrm{m}$ was used. The water-conductivity correction $\sigma_{w}{ }^{0.28}$ compensates the dependency of $\frac{\left(\sigma^{\prime \prime}\left(\sigma_{w}\right)\right)^{2.27}}{\left(\sigma_{b u l k}\left(\sigma_{w}\right)\right)^{1.12}}$ on the water conductivity $\sigma_{w}$. Equation (13), and henceforth equation (9), can be evaluated from the inversion parameters of the BIC model and from the knowledge of the water solution.

Note that the dependence of the k-estimation on groundwater conductivity is weak. Indeed, the power of 0.28 for $\sigma_{w}$ in equation (13) means that, for example, a 10-fold variation in water conductivity causes less than a 2-fold variation in IP-estimated permeability. The effect of the uncertainty of the exponent $a$ of equation (12) on equation (13), as well as the importance of the water conductivity correction in comparison to the other uncertainties in the IP-derived permeability estimation, are discussed in detail in the next paragraph and in the results section.

For the correction of the water chemistry, A. Weller et al. [2011] suggest $C_{f}=2$ for $\mathrm{CaCl}_{2}$ and $C_{f}=1$ for $\mathrm{NaCl}$; for other ions, no suggestion was made. Realizing that the original suggestion is based on a sparse data set and that numerous cations and anions are present in the field-collected water samples with varying molecular concentration, it is difficult to apply an appropriate correction. Therefore, in our $k$-estimation the correction factor $C_{f}$ was not accounted for.

For the evaluation of equation (13), the imaginary conductivity at frequency $f=1 \mathrm{~Hz}$ can be computed from the inversion parameters $\left\{\sigma_{\max }^{\prime \prime}, \tau_{\sigma}, C\right\}$. Actually, as it is shown in the results section, minor differences exist between $\sigma_{\text {max }}^{\prime \prime}$ and $\sigma^{\prime \prime}(f=1 \mathrm{~Hz})$, so $\sigma_{\text {max }}^{\prime \prime}$ is used in equation (13) in our computations, also because this simplifies the propagation of the inversion parameter uncertainty into the parameter uncertainty.

As an alternative to equation (9) and (13) and the inversion in terms of the BIC parameters of equation (6), it is possible to derive the permeability from equations (10) and (12) and the inversion in terms of the MIC parameters of equation (2), i.e. it is possible to use $\sigma_{0}$ instead of $\sigma_{b u l k}$. In this 
study we prefer to follow the first approach for two reasons: i) the effect of surface conductivity in the estimation of the formation factor is taken into account (i.e. an estimate of the true formation factor $F$ is used instead of an estimate of the apparent formation factor $F^{\prime}$ ); ii) the use of the BIC model instead of the MIC model is better suited for permeability estimation from surface IP data, as shown recently by Maurya et al. [2018]. In fact, the use of the BIC model in 2D/3D imaging practically imposes a geometrical constraint between the spatial distribution of the inverted imaginary conductivity $\sigma^{\prime \prime}$ and the spatial distribution of the total DC conductivity $\sigma_{0}$ section, so that a chargeable area in the inversion model is also conductive. On the contrary, when $\sigma_{\text {surf }}^{\prime}$ gives a negligible contribution to $\sigma_{0}$, no geometrical constraint is enforced between the $\sigma^{\prime \prime}$ and $\sigma_{0}$ spatial distributions and the BIC and MIC models give equivalent results. This feature reduces the equivalences in the $\sigma_{0}$ imaging and helps in retrieving inversion models more representative of the site geology, and henceforth better permeability estimations [Maurya et al., 2018]. However, in this study the high vertical resolution of the El-log technique avoids equivalence problems in the $\sigma_{0}$ estimation, and the permeability estimates retrieved by the MIC and BIC inversions are of comparable quality (results not shown for brevity).

\subsubsection{Evaluation of prediction quality and uncertainty on permeability estimates}

The total uncertainty on the IP-derived permeability estimation depends on the uncertainties of the petrophysical relations, as well as on the uncertainty of the inversion parameters used in the computations. The prediction quality of equation (9) and (10) was defined by Weller et al [2015a] in terms of the average absolute deviation (in log space) between the IP-derived permeability $k_{I P}$ and measured permeability $k_{\text {meas }}$ :

$d=\frac{1}{N} \cdot \sum_{i=1}^{N}\left|\log _{10}\left(k_{I P_{i}}\right)-\log _{10}\left(k_{\text {meas }}\right)\right|$ 
Using equation (9) Weller et al [2015a] found for unconsolidated samples a value $d=0.386$, which implies that the IP-derived permeability estimates are on average accurate within an Uncertainty Factor (UF) of:

$U F_{I P}=10^{d}=10^{0.386} \cong 2.4$

In order to estimate the uncertainty of the correction of the imaginary conductivity due to the variable water conductivity, the standard deviation $S T D_{a}$ of the exponent $a$ of equation (12) is used. Indeed, the confidence interval of the permeability estimates can be computed using equation (9) and (13) with the confidence limits of the exponent $\left[a-S T D_{a} ; a+S T D_{a}\right]$. This leads to an Uncertainty Factor of:

$U F_{\sigma_{W}}=\left(\frac{\sigma_{W}}{\sigma_{f}}\right)^{0.27}$

Combining equation (9) and (13), the upper limit $a+S T D_{a}=0.49$ (practically the value used and suggested by Weller et al [2015a]) gives a total water-conductivity correction $\sigma_{w}{ }^{0.008}$, while the lower limit $a-S T D_{a}=0.25$ gives $\sigma_{w}{ }^{0.55}$. This means that in the upper limit the waterconductivity correction is practically equivalent to no correction, because of the small exponent of $\sigma_{w}$, while with the lower limit the correction depends approximately on the square root of $\sigma_{W}$.

The final contribution to the permeability uncertainty derives from the uncertainty on the inversion parameters. This uncertainty can be computed from the covariance of the estimator error for linear mapping $\boldsymbol{C}_{\text {est }}$ described by Tarantola and Valette [1982]

$\boldsymbol{C}_{e s t}=\left[\boldsymbol{G}^{T} \boldsymbol{C}_{d}^{*-1} \boldsymbol{G}\right]^{-1}$

where $\boldsymbol{G}$ represents the Jacobian of the last iteration of the inversion and the diagonal matrix $\boldsymbol{C}_{d}^{*}$ is a modified data covariance matrix. The modification consists of taking as diagonal elements $\boldsymbol{C}_{d_{i, i}}^{*}$ the maximum between the data variances $C_{d_{i, i}}$ and the squared misfit $\left(f_{i}-d_{i}\right)^{2}$, where $i$ represents the 
index of the data vector, $d_{i}$ is the $i^{\text {th }}$ datum and $f_{i}$ is the corresponding forward response. The use of $\boldsymbol{C}_{d}^{*}$ instead of the classic $C_{d}$ in equation (17) avoids to underestimate the parameter uncertainty if some data are not fitted within the standard deviation in the inversion process. Once the uncertainty on the inversion parameters is computed, the inversion-derived uncertainty on the permeability estimates can be computed as:

$S T D_{k_{I P}}=\sqrt{\left(\frac{\partial k}{\partial \sigma_{b u l k}} \cdot S T D_{\sigma_{b u l k}}\right)^{2}+\left(\frac{\partial k}{\partial \sigma^{\prime \prime}} \cdot S T D_{\sigma_{\text {max }}^{\prime \prime}}\right)^{2}}$

where $\frac{\partial k}{\partial \sigma_{\text {bulk }}}$ and $\frac{\partial k}{\partial \sigma^{\prime \prime}}$ are the partial derivatives of the permeability formula obtained combining equation (9) and equation (13), STD $D_{\sigma_{b u l k}}$ is the inversion uncertainty on the bulk conductivity and $S T D_{\sigma_{\max }^{\prime \prime}}$ is the inversion uncertainty on the maximum imaginary conductivity. The Uncertainty Factor derived from the inversion uncertainty can then be computed as:

$U F_{\text {inversion }}=1+\frac{S T D_{k_{I P}}}{k_{I P}}$

Finally, the total uncertainty on the permeability estimates is obtained multiplying the three uncertainty factors of equation (15), equation (16) and equation (19):

$U F_{\text {total }}=U F_{I P} \cdot U F_{\sigma_{W}} \cdot U F_{\text {inversion }}$

\section{Results}

\subsection{Inversion models and data fit}

Figure 4 presents the inversion models of the three El-logs, for all inversion parameters, together with the parameter uncertainty computed through equation (17), while Figure 5 shows the fit of the DC data and of representative IP decays of the three inversions. The data standard deviations used in the inversion and for the computation of the parameter uncertainty were $1 \%$ on resistivity and 
$10 \%$ on each gate of the IP decays, plus a voltage noise floor $V_{\text {noise }}=0.1 \mathrm{mV}$ (see Olsson et al. [2015] for details on the computation of the total data uncertainty from $V_{\text {noise }}$ and the relative standard deviation). In Figure 4 it is seen that $\sigma_{\max }^{\prime \prime}$ is a well resolved inversion parameter, with uncertainty comparable to the $\sigma_{\text {bulk }}$ uncertainty, while the frequency exponent $C$ and, even more, the time constant $\tau_{\sigma}$ present significantly wider confidence intervals. The small $\sigma_{\text {max }}^{\prime \prime}$ uncertainty derives from the re-parameterization of the Cole-Cole model: when inverting the same data with the classic Cole-Cole model, the uncertainty on $m_{0}$ is much higher, due to the high correlation between $m_{0}$ and the frequency exponent $C$ [G. Fiandaca et al., 2018; Madsen et al., 2017].

In Figure 4 the imaginary conductivity $\sigma^{\prime \prime}$ at frequency $f=1 \mathrm{~Hz}$, computed from the inversion parameters $\left\{\sigma_{\text {max }}^{\prime \prime}, \tau_{\sigma}, C\right\}$, is shown together with the $\sigma_{\max }^{\prime \prime}$ inversion estimates, because $\sigma^{\prime \prime}(f=$ $1 \mathrm{~Hz}$ ) is needed in equations (9) and (13). The frequency exponent $C$ of the Cole-Cole parameterization (equation 1) is generally small, resulting in broad spectra, so that $\sigma^{\prime \prime}(f=1 \mathrm{~Hz})$ and $\sigma_{\max }^{\prime \prime}$ are close to each other. In particular, for this data set the (geometric) mean difference between $\sigma^{\prime \prime}(f=1 \mathrm{~Hz})$ and $\sigma_{\text {max }}^{\prime \prime}$ ranges only from $4 \%$ (El-log E1) to $10 \%$ (El-log E3).

Consequently, the difference in $k$-prediction using $\sigma^{\prime \prime}(f=1 \mathrm{~Hz})$ and $\sigma_{\text {max }}^{\prime \prime}$ is on average only $6 \%$ (actually, in favor of the $\sigma_{\text {max }}^{\prime \prime}$ estimates), which is negligible compared to the overall scatter between permeability values derived from IP and GSA/ST estimates seen in the next sections. Therefore, $\sigma_{\max }^{\prime \prime}$ will be used instead of $\sigma^{\prime \prime}(f=1 \mathrm{~Hz})$ in the further calculations.

\subsection{Lithology versus $\sigma_{b u l k}, \sigma_{\max }^{\prime \prime}$ and gamma radiation}

The maximum imaginary conductivity $\left(\sigma_{\max }^{\prime \prime}\right)$ and bulk conductivity $\left(\sigma_{\text {bulk }}\right)$, retrieved from the Cole-Cole BIC inversion of TD SIP data from El-log E1 is shown in Figure $6 \mathrm{~b}$ and $6 \mathrm{c}$. The corresponding gamma log together with a detailed lithological log obtained from the sediment cores of Sc1 are shown in Figure 6a. The El-log TD SIP data were recorded to $27 \mathrm{~m}$ depth, whereas the gamma $\log$ is available to $29.5 \mathrm{~m}$. The uncertainty on the estimates of $\sigma_{\text {bulk }}$ and $\sigma_{\text {max }}^{\prime \prime}$, from a 
linearized sensitivity analysis [Auken et al., 2014] is indicated by thin lines. A very good correlation between different sediment types and $\sigma_{\max }^{\prime \prime}$ can be seen. The Quaternary glacial sands (medium to coarse) exhibit on average low $\sigma_{\max }^{\prime \prime}$ values $(\sim 0.01 \mathrm{mS} / \mathrm{m})$. The boundary between the Quaternary and Tertiary sand deposits (where mica sand unit starts) are observed in $9.8 \mathrm{~m}$ depth where a sharp transition in gamma $\log$ and $\sigma_{\max }^{\prime \prime}$ can be seen. The mica-rich sands (fine to medium) shows relatively higher $\sigma_{\max }^{\prime \prime}$ values. Interbedded thin clayey and silty layers (around $13 \mathrm{~m}$ depth) in the Tertiary formation are characterized by the higher gamma peaks and correlates very well with a high $\sigma_{\max }^{\prime \prime}$. The quartz sands shows only small variations in $\sigma_{\text {bulk }}$ and $\sigma_{\max }^{\prime \prime}$, which is also well supported by relatively low gamma count ( 10 CPS). Overall, it can be seen that the lithological variations correlate well with $\sigma_{\max }^{\prime \prime}$, which is a key parameter used for predicting $k$.

\subsection{Correlation between $S_{p o r}$ and $\sigma_{m a x}^{\prime \prime}$}

In the laboratory, a robust relationship between $\sigma^{\prime \prime}$ and $S_{\text {por }}$ that explains multiple data sets was found [A. Weller et al., 2010]. Also, although no longer explicitly in the equations, the permeability prediction from $\sigma^{\prime \prime}$ is implicitly based on its correlation with $S_{\text {por }}$. Therefore, we investigate this relationship in El-log E1. Figure 6d shows the correlation between $S_{\text {por }}$ and $\sigma_{\max }^{\prime \prime}$, corrected for water conductivity following equation (10). As observed from the cross plot, a single $C_{p}$ value cannot explain the specific polarizability of all sediment types. This discrepancy has also been observed in the laboratory-derived results presented by Andreas Weller et al. [2015b] who found that if $S_{p o r}$ is measured with the BET method, different values of $C_{p}$ are required to explain the relationship between $S_{\text {por }}$ and $\sigma^{\prime \prime}$. The relationships derived from their laboratory measurements for different $C_{p}$ values are shown for reference in Figure 6d. Andreas Weller et al. [2015b] found that sand mixed with muscovite and illite, has a higher $C_{p}$ value $\left(24 \times 10^{-12} \mathrm{~S}\right)$ than the common value of $C_{p}\left(10 \times 10^{-12} \mathrm{~s}\right)$ suggested by $A$. Weller et al. [2010]. We observed the same trend for mica rich sands in our data. For quartz-clean sands Andreas Weller et al. [2015b] observed a lower $C_{p}$ 
value $\left(5.8 \times 10^{-12} \mathrm{~S}\right)$, which in our case is replicated by the glacial sands showing lower $C_{p}$ values, although they are not as uniform as the laboratory sands. Overall, the estimated $\sigma_{\max }^{\prime \prime}$ deviates from $C_{p} S_{\text {por }}$ less than one order of magnitude for most of the samples, suggesting that estimates of permeability within one order of magnitude can be expected from IP data in this study.

\subsection{Permeability estimation from El-log TD SIP measurements}

\subsubsection{Effect of water conductivity}

Figure 7 shows the variability of the water conductivity $\sigma_{W}$ measured in the three El-logs and its effect on the permeability estimates. In particular, the $\sigma_{W}$ values measured on the screens close to the El-logs are shown together with: $\sigma_{W}$ interpolated into depth-logs; the inverted $\sigma_{b u l k}$; the permeability, computed through equations (9) and (13); the confidence interval of the $\sigma_{W}$ correction, computed through equation (16); the water tables levels. The permeability estimates are shown only below the water table levels, because water saturation is required in equation (9). The $\sigma_{W}$ interpolation was performed individuating depth ranges of uniform conductivity based the $\sigma_{b u l k}$ trends, and assigning the $\sigma_{W}$ value of the nearest measurement. The confidence interval of the $\sigma_{W}$ correction, which practically comprises the permeability estimates without correction at all, is small when compared to the prediction quality of equation (9), i.e. $U F_{I P}=2.4$ (equation 15). In particular, the $\sigma_{W}$ correction is practically negligible in El-log E2, i.e. the El-log placed in the core of the landfill leachate plume, because there the water conductivity is relatively high, similar to the reference solution used in the laboratory measurements (i.e. $\sigma_{f}=100 \mathrm{mS} / \mathrm{m}$ ). In Figure 7 the water table levels are also shown:

\subsubsection{Comparison with ST and GSA estimates}

Permeability for all El-logs, computed using equation (9) and equation (13) with interpolated $\sigma_{W}$ depth-logs, is shown in Figure 8, together with the confidence limits derived from the total Uncertainty Factor $U F_{\text {total }}$ of equation (20). Furthermore, Figure 8d shows a zoom-in of El-log E2, 
where all the correction factors contributing to $U F_{\text {total }}$ are also shown. In particular, it is seen that the smallest contribution to $U F_{\text {total }}$ is due to $U F_{\sigma_{W}}$ (equation 16), followed by $U F_{\text {inversion }}$ (equation 19) and $U F_{I P}$ (equation 15).

In all El-logs, permeability calculated using grain size analyses (GSA) and measured with slug-tests (ST) are shown for comparison. In E1, the IP-derived permeability agrees well with the GSA and ST estimates, both quantitatively and in terms of depth trend. Overall, the estimates are within one order of magnitude, except in the clay-rich sands at depths around $13.8 \mathrm{~m}$ (not shown in the figure), where smaller values are obtained from the grain size analysis (and where the applicability of the GSA formulae is questionable, due to the high clay content). Also around 6-10 $\mathrm{m}$ depth, the IPderived $k$ estimates show larger deviation from GSA estimates. However, in this interval the ST estimate shows closer correspondence to IP-derived $k$ values. Similar results can also be seen in the two other El-logs (E2 and E3). Furthermore, the ST permeability estimates fall always within the total uncertainty $U F_{\text {total }}$ of the IP-derived estimates, and the GSA and IP-derived estimates almost always differ less than their combined uncertainties. Cross plots between $k$ derived from GSA and ST and IP derived $k$ are shown in Figure 9. Published data from Andreas Weller et al. [2015a], which encompass a wide range of unconsolidated sediments are also shown on the plot. Overall, it is seen that the permeability estimations from El-log TD SIP data show an agreement with the slug tests of quality comparable to that reported by Andreas Weller et al. [2015a] on laboratory data. The average deviations (equation 14) from the GSA k-estimates of El-log E1, E2 and E3 are $d_{E 1, G S A}=$ $0.85, d_{E 2, G S A}=0.63, d_{E 3, G S A}=0.70$, respectively; the average deviation from the slug tests on all the El-logs is $d_{S T}=0.23$. The average deviation from both GSA and slug tests all the El-logs is $d_{\text {total }}=0.679$, practically identical to the average deviation $d_{\sigma_{W}=\sigma_{f}}=0.684$ obtained when using the constant value $\sigma_{W}=\sigma_{f}=100 \mathrm{mS} / \mathrm{m}$ in equation (13), confirming the negligible effect of $\sigma_{W}$ 
on the quality of the permeability estimation. For comparison, the average deviation found in Andreas Weller et al. [2015a] from laboratory measurements is $d_{\text {lab }}=0.39$.

\section{Discussion}

IP-derived $k$, values were compared with values obtained from GSA and slug tests. A better agreement was obtained between IP-derived $k$ values and slug tests, than between IP and GSA estimates. When the grain size data are used, some data points fall outside of the bounds reported by Weller et al. [2015a].This likely reflects the limitations of the grain size estimates of permeability as much as the limitations of the IP methodology for k estimation. It is worth to note that values estimated from grain size analyses are based on a span of empirical equations, which give different permeability estimates. The variation of the GSA permeability estimates reflects the fact that the grain size distribution represents only one factor in permeability prediction: material with identical grain size distribution can be compacted in different ways resulting in different levels of packing, with varying porosity, and consequently varying permeability. On the contrary, IP spectra also depend on the packing procedure [Bairlein et al., 2014] and, in this sense, might be more accurate than the GSA analysis. Furthermore, the grain size analyses were performed on samples which not in all cases represent the actual geological layer due to losses during sampling (at least for the samples not retrieved from cores, i.e. Bh2 and Bh3). This would inevitably affect any $k$ prediction which relies on empirical relationship with in-situ structures of the sediment. All this suggests that more trust should be put on the $k$ values obtained through slug tests when evaluating the predictive quality of $k$ from IP data, which were recorded in the undisturbed formation. In hindsight, it would have been better to design the survey with more slug tests than grain size analyses. Therefore, it is suggested that future studies expand the comparison to a larger data set of small-scale slug tests and other methods for in-situ permeability estimation [e.g., McCall et al., 2014]. 
El-log E2 is located very close to the leachate plume from the Grindsted landfill and has a significantly higher water electrical conductivity (50 to $192 \mathrm{mS} / \mathrm{m}$ ) compared to $\mathrm{E} 1$ (17 to 52 $\mathrm{mS} / \mathrm{m})$. Importantly, we found no evidence that the presence of the plume and the increased electrical conductivity affected the quality of $k$ prediction from IP data, and the water-conductivity correction in the k-prediction itself is almost negligible, when compared to the other uncertainties in the estimation. This is important as a wide range of water electrical conductivities are found in unconsolidated sediments where this method would be useful, and especially in contaminated site investigations.

In equation (13) $C_{f}$ accounts for the possible differences in ionic species in the reference and actual solution, but the lack of laboratory evidence on how to correct for solution with a variety of cations and anions prevented to apply the correction. The indication of A. Weller et al. [2011] about $C_{f}$ (i.e. $C_{f}=2$ for $\mathrm{CaCl}_{2}$ and $C_{f}=1$ for $\mathrm{NaCl}$ ), together with the exponent for $C_{f}$ in equation (13) (i.e. 2.27), suggest a significant role of the chemical composition of the solution on the permeability prediction. Significant variations in inorganic water chemistry are present among the three boreholes, but also vertically in each borehole. Nevertheless, the quality of $k$ prediction from IP data in the three El-logs is similar, without any significant bias, implying that $C_{f}$ for solutions with a variety of cations and anions might be close to 1 . The data on the chemical composition of the water exist and is provided as supplementary document in table $\mathrm{S} 1$ in supplementary material: it will be possible to further analyze the data if new laboratory/theoretical evidence on $C_{f}$ will be presented.

Another topic that deserves more investigation is the role of the IP spectral content on the permeability prediction. In this study a spectral inversion in terms of the BIC Cole-Cole model was performed, and the maximum imaginary conductivity $\sigma_{\max }^{\prime \prime}$ instead of $\sigma^{\prime \prime}$ at $1 \mathrm{~Hz}$ was used in the permeability estimation, mainly because $\sigma_{\max }^{\prime \prime}$ and $\sigma^{\prime \prime}$ at $1 \mathrm{~Hz}$ were very similar. However, the BIC Cole-Cole inversion allows for studying if better correlations exist between other parameters 
retrieved from the IP spectrum (for instance the normalized chargeability $m_{n}$ also used in Weller et al. [2015a]) and the GSA/ST estimates. This topic will be investigated in future studies.

Remarks should be made about the applicability of the proposed method with regard to site lithology and water saturation. Equations (9) and (13) are valid only for saturated unconsolidated sediments. Studies have been presented where a correction for water saturation was performed on the DC and imaginary conductivity for permeability estimation [e.g. Kemna et al., 2004], but the correction for water saturation and its general applicability is beyond the scope of this study. Regarding the site lithology, in Andreas Weller et al. [2015a] equations were proposed also for sandstones, but it was found that the formation factor, instead of the imaginary conductivity, exerts the dominant control on the permeability. This presents substantial challenges for the field-scale prediction of permeability from electric measurements, because an accurate estimation of the formation factor is required. The BIC modeling proposed in this study might help in this respect, because it separates the bulk conductivity from the DC surface conductivity, but its effectiveness has yet to be evaluated on surveys carried out on sandstones.

Finally, a brief comment on the choice of the $\sigma^{\prime \prime}$ approach for permeability estimation instead of the approach based on the relaxation time [e.g. Revil et al., 2015]. This choice is a natural consequence of the uncertainties of the inversion parameters presented in Figure 4: $\sigma_{\text {max }}^{\prime \prime}$ is much better resolved than $\tau_{\sigma}$. This argument is even more important when considering that $\tau_{\sigma}$ is much more difficult to be imaged from surface measurements instead of borehole measurements. Consequently, we believe that the $\sigma^{\prime \prime}$ approach is better suited for field applications.

\section{Conclusion}

In the present study, we have shown that TD SIP can be reliably used for estimating permeability of unconsolidated formations at field scale. For this purpose, high quality spectral TD SIP data were acquired in three boreholes using the El-log drilling technique. A full decay time domain inversion 
algorithm employing a re-parameterized Cole-Cole model was used. Permeability was calculated by using the empirical relations for unconsolidated sediments found in the laboratory without any further calibration and the IP-derived $k$ values were compared to those estimated by grain size analyses and measured by slug tests. The $k$-estimation from IP data correlates very closely with the slug test measurements and appears to be within one order of magnitude of k-estimates form grain size analyses data. This is a similar prediction quality as observed from laboratory measurements.

Furthermore, the effect of pore water conductivity is weak in the laboratory-derived formula for the $k$ estimates, and negligible when compared to the other uncertainties in the computations, because the combined influence on the bulk and imaginary conductivities almost cancels out the effect in the permeability estimation. This theoretical prediction was confirmed in our field results, in which equivalent quality of the permeability estimations was found in boreholes with significant differences in water conductivity, with and without taking into account the actual values of the water conductivity in the computations. These new findings pave the way for detailed and inexpensive mapping of permeability on saturated, unconsolidated sediments in the field, using both borehole and surface measurements techniques, including sites with high and varying pore water conductivity.

\section{Acknowledgement}

Support was provided by the research project GEOCON (contract 1305-00004B) funded by Innovation Fond Denmark. The data used are listed in the supplementary documents. The paper is also a part of the water CEnter for Water Technology (WATEC) at Aarhus University.

We thank the two anonymous reviewers, the associate editor Lee Slater and Prof. Andreas Weller, which reviewed the paper in its first submission, for their valuable comments that helped in improving significantly the manuscript. 


\section{References}

Alyamani, M. S., and Z. Şen (1993), Determination of Hydraulic Conductivity from Complete Grain-Size Distribution Curves, Ground Water, 31(4), 551-555.

Archie, G. E. (1942), The electrical resistivity $\log$ as an aid in determining some reservoir characteristics, Trans. AIME, 146, 54-62.

Attwa, M., and T. Günther (2013), Spectral induced polarization measurements for predicting the hydraulic conductivity in sandy aquifers, Hydrol. Earth Syst. Sci., 17(10), 4079-4094. 10.5194/hess-17-4079-2013

Auken, E., et al. (2014), An overview of a highly versatile forward and stable inverse algorithm for airborne, ground-based and borehole electromagnetic and electric data, Explor. Geophys, 113.

Bairlein, K., A. Hördt, and S. Nordsiek (2014), The influence on sample preparation on spectral induced polarization of unconsolidated sediments, Near Surface Geophysics, 12(5), 667677.

Barr, D. W. (2001), Coefficient of permeability determined by measurable parameters, Ground Water, 39(3), 356-361.

Beyer, W. (1964), Zur Bestimmung der Wasserdurchlässigkeit von Kiesen und Sanden aus der Kornverteilungskurve, $W W T, 14(6), 165-168$.

Białas, Z. (1966), O usrednianiu wspolczynnikow filtracji z zastosowaniem elektronicznej cyfrowej maszyny matematycznej [Averaging filter coefficients using digital electronic mathematical machines], Przedsiebiorstwo Geologiczne we Wroclawiu, Warsaw, Poland, 47-50.

Binley, A., L. D. Slater, M. Fukes, and G. Cassiani (2005), Relationship between spectral induced polarization and hydraulic properties of saturated and unsaturated sandstone, Water Resources Research, 41(12), 1-13.

Binley, A., J. Keery, L. Slater, W. Barrash, and M. Cardiff (2016), The hydrogeologic information in cross-borehole complex conductivity data from an unconsolidated conglomeratic sedimentary aquifer, Geophysics, 81(6), E409-E421.

Bjerg, P. L., K. Rugge, J. K. Pedersen, and T. H. Christensen (1995), Distribution of redox-sensitive groundwater quality parameters downgradient of a landfill (Grindsted, Denmark), Environmental Science \& Technology, 29(5), 1387-1394. 10.1021/es00005a035

Bouwer, H., and R. Rice (1976), A slug test for determining hydraulic conductivity of unconfined aquifers with completely or partially penetrating wells, Water resources research, 12(3), 423-428. 
Brunauer, S., P. H. Emmett, and E. Teller (1938), Adsorption of gases in multimolecular layers, $J$. Am. Chem. Soc, 60(2), 309-319.

Börner, F. D., J. R. Schopper, and A. Weller (1996), Evaluation of transport and storage properties in the soil and groundwater zone from induced polarization measurements, Geophysical Prospecting, 44(4), 583-601.

Chapuis, R. P. (2004), Predicting the saturated hydraulic conductivity of sand and gravel using effective diameter and void ratio, Canadian geotechnical journal, 41(5), 787-795.

Chen, J., S. S. Hubbard, K. H. Williams, A. F. Orozco, and A. Kemna (2012), Estimating the spatiotemporal distribution of geochemical parameters associated with biostimulation using spectral induced polarization data and hierarchical Bayesian models, Water Resour. Res, 48, $1-25$.

Christensen, T. H., P. Kjeldsen, P. L. Bjerg, D. L. Jensen, J. B. Christensen, A. Baun, H. J. Albrechtsen, and C. Heron (2001), Biogeochemistry of landfill leachate plumes, Applied Geochemistry, 16(7-8), 659-718. 10.1016/s0883-2927(00)00082-2

Devlin, J. F. (2015), HydrogeoSieveXL: an Excel-based tool to estimate hydraulic conductivity from grain-size analysis, Hydrogeology Journal, 23(4), 837-844.

Fiandaca, G., P. K. Maurya, and L. M. Madsen (2017), Re-parameterization of the Cole-Cole model for improved spectral inversion of induced polarization data, in 23rd European Meeting of Environmental and Engineering Geophysics, edited, Near Surface Geoscience, Malmo, Sweden

Fiandaca, G., L. M. Madsen, and P. K. Maurya (2018), Re-parameterizations of the Cole-Cole model for improved spectral inversion of induced polarization data, in press Near Surface Geophysics. https://doi.org/10.3997/1873-0604.2017065

Fiandaca, G., E. Auken, A. Gazoty, and A. V. Christiansen (2012), Time-domain induced polarization: Full-decay forward modeling and 1D laterally constrained inversion of ColeCole parameters, Geophysics, 77(3), E213-E225.

Florsch, N., A. Revil, and C. Camerlynck (2014), Inversion of generalized relaxation time distributions with optimized damping parameter, Journal of Applied Geophysics, 109, 119132. http://dx.doi.org/10.1016/j.jappgeo.2014.07.013

Gazoty, A., G. Fiandaca, J. Pedersen, E. Auken, and A. V. Christiansen (2012), Mapping of landfills using time-domain spectral induced polarization data: The Eskelund case study, Near Surface Geophysics, 10(6), 575-586. 
Hazen, A. (1892), Some physical properties of sands and gravels with special reference to their filtration, Massachusetts State Board of Health, 24th Annual Report(34), 539-556.

Heron, G., P. L. Bjerg, P. Gravesen, L. Ludvigsen, and T. H. Christensen (1998), Geology and sediment geochemistry of a landfill leachate contaminated aquifer (Grindsted, Denmark), Journal of Contaminant Hydrology, 29(4), 301-317. 10.1016/s0169-7722(97)00028-4

Hinsby, K., P. L. Bjerg, L. J. Andersen, B. Skov, and E. V. Clausen (1992), A mini slug test method for determination of a local hydraulic conductivity of an unconfined sandy aquifer, Journal of Hydrology, 136(1), 87-106. http://dx.doi.org/10.1016/0022-1694(92)90006-H

Hvorslev, M. (1951), Time lag and soil permeability in groundwater observations, US Army Corps Eng. Waterways Exp. Sta. Bull, 36.

Hördt, A., R. Blaschek, A. Kemna, and N. Zisser (2007), Hydraulic conductivity estimation from induced polarisation data at the field scale - the Krauthausen case history, Journal of Applied Geophysics, 62(1), 33-46.

Hördt, A., A. Druiventak, R. Blaschek, F. Binot, A. Kemna, P. Kreye, and N. Zisser (2009), Case histories of hydraulic conductivity estimation with induced polarization at the field scale, Near Surface Geophysics, 7(5-6), 529-545.

Johansson, S., G. Fiandaca, and T. Dahlin (2015), Influence of non-aqueous phase liquid configuration on induced polarization parameters: Conceptual models applied to a timedomain field case study, Journal of Applied Geophysics, 123, 295-309. http://dx.doi.org/10.1016/j.jappgeo.2015.08.010

Kemna, A., A. Binley, and L. Slater (2004), Crosshole IP imaging for engineering and environmental applications, Geophysics, 69(1), 97-107.

Kjeldsen, P., A. Grundtvig, P. Winther, and J. S. Andersen (1998), Characterization of an old municipal landfill (Grindsted, Denmark) as a groundwater pollution source: landfill history and leachate composition, Waste management \& research, 16(1), 3-13.

Kjeldsen, P., P. L. Bjerg, K. Rugge, T. H. Christensen, and J. K. Pedersen (1998), Characterization of an old municipal landfill (Grindsted, Denmark) as a groundwater pollution source: landfill hydrology and leachate migration, Waste Management \& Research, 16(1), 14-22. $10.1177 / 0734242 \times 9801600103$

Kozeny, J. (1953), Das Wasser im Boden. Grundwasserbewegung, Hydraulik: Ihre Grundlagen und praktische Anwendung, 380-445.

Krumbein, W., and G. Monk (1943), Permeability as a function of the size parameters of unconsolidated sand, Transactions of the AIME, 151(01), 153-163. 
Krüger, E. (1918), Die Grundwasserbewegung, Internationale Mitteilungen für Bodenkunde, 8, 105. Madsen, L. M., G. Fiandaca, E. Auken, and A. V. Christiansen (2017), Time-domain induced polarization - an analysis of Cole-Cole parameter resolution and correlation using Markov Chain Monte Carlo inversion, Geophysical Journal International, 211(3), 1341-1353. 10.1093/gji/ggx355

Maurya, P. K., V. Rønde, G. Fiandaca, N. Balbarini, E. Auken, P. L. Bjerg, and A. V. Christiansen (2017), Detailed landfill leachate plume mapping using 2D and 3D electrical resistivity tomography - with correlation to ionic strength measured in screens, Journal of Applied Geophysics, 138(March 2017), 1. http://dx.doi.org/10.1016/j.jappgeo.2017.01.019

Maurya, P. K., N. Balbarini, I. Møller, V. Rønde, A. V. Christiansen, P. L. Bjerg, E. Auken, and G. Fiandaca (2018), Subsurface imaging of water electrical conductivity, hydraulic permeability and lithology at contaminated sites by induced polarization, Geophysical Journal International, 213(2), 770-785. https://doi.org/10.1093/gji/ggy018

McCall, W., T. M. Christy, D. Pipp, M. Terkelsen, A. Christensen, K. Weber, and P. Engelsen (2014), Field Application of the Combined Membrane-Interface Probe and Hydraulic Profiling Tool (MiHpt), Groundwater Monitoring \& Remediation, 34(2), 85-95.

Nordsiek, S., and A. Weller (2008), A new approach to fitting induced-polarization spectra, Geophysics, 73(6), F235-F245.

Olsson, P.-I., G. Fiandaca, J. J. Larsen, T. Dahlin, and E. Auken (2016), Doubling the spectrum of time-domain induced polarization by harmonic de-noising, drift correction, spike removal, tapered gating and data uncertainty estimation, Geophysical Journal International, 207(2), 774-784. 10.1093/gji/ggw260

Olsson, P. I., T. Dahlin, G. Fiandaca, and E. Auken (2015), Measuring time-domain spectral induced polarization in the on-time:decreasing acquisition time and increasing signal-tonoise ratio, Journal of Applied Geophysics, 2015(123), 6. http://dx.doi.org/10.1016/j.jappgeo.2015.08.009

Orozco, A. F., K. H. Williams, P. E. Long, S. S. Hubbard, and A. Kemna (2011), Using complex resistivity imaging to infer biogeochemical processes associated with bioremediation of an uranium-contaminated aquifer, Journal of Geophysical Research: Biogeosciences, 116(G3), G03001.

Orozco, A. F., A. Kemna, C. Oberdörster, L. Zschornack, C. Leven, P. Dietrich, and H. Weiss (2012), Delineation of subsurface hydrocarbon contamination at a former hydrogenation 
plant using spectral induced polarization imaging, Journal of Contaminant Hydrology, 136137, 131-144.

Revil, A. (2012), Spectral induced polarization of shaly sands: Influence of the electrical double layer, Water Resour. Res, 48(2), W02517.

Revil, A., and N. Florsch (2010), Determination of permeability from spectral induced polarization in granular media, Geophysical Journal International, 181(3), 1480-1498.

Revil, A., A. Binley, L. Mejus, and P. Kessouri (2015), Predicting permeability from the characteristic relaxation time and intrinsic formation factor of complex conductivity spectra, Water Resources Research, 51(8), 6672-6700. 10.1002/2015WR017074

Rosas, J., O. Lopez, T. M. Missimer, K. M. Coulibaly, A. H. A. Dehwah, K. Sesler, L. R. Lujan, and D. Mantilla (2014), Determination of Hydraulic Conductivity from Grain-Size Distribution for Different Depositional Environments, Groundwater, 52(3), 399-413. $10.1111 /$ gwat. 12078

Santamarina, J., K. Klein, Y. Wang, and E. Prencke (2002), Specific surface: determination and relevance, Canadian Geotechnical Journal, 39(1), 233-241.

Sato, H. K. (2000), Potential field from a dc current source arbitrarily located in a nonuniform layered medium, Geophysics, 65(6), 1726-1732.

Slater, L. (2007), Near surface electrical characterization of hydraulic conductivity: From petrophysical properties to aquifer geometries - A review, Surveys in Geophysics, 28(2-3), 169-197.

Slater, L., and D. P. Lesmes (2002), Electrical-hydraulic relationships observed for unconsolidated sediments, Water Resources Research, 38(10), 31-31-31-13. 10.1029/2001WR001075

Slater, L. D., and D. Lesmes (2002), IP interpretation in environmental investigations, Geophysics, 67(1), 77-88.

Slichter, C. S. (1899), Theoretical investigation of the motion of ground waters, US Department of the Interior, Geological Survey, Water Resources Division, Ground Water Branch.

Springer, R., and L. Gelhar (1991), Characterization of large-scale aquifer heterogeneity in glacial outwash by analysis of slug tests with oscillatory response, Cape Cod, Massachusetts, US Geol. Surv. Water Res. Invest. Rep, 91, 36-40.

Switzer, A. D., and J. Pile (2015), Grain size analysis, Handbook of Sea-Level Research, 331.

Sørensen, K. I., and F. Larsen (1999), Ellog Auger Drilling: 3-in-one Method for Hydrogeological Data Collection, Ground Water Monitoring \& Remediation, 19(4), 97-101. 
Tarantola, A., and B. Valette (1982), Generalized nonlinear inverse problems solved using a least squares criterion, Reviews of Geophysics and Space Physics, 20(2), 219-232.

Tarasov, A., and K. Titov (2013), On the use of the Cole-Cole equations in spectral induced polarization, Geophysical Journal International, 195(1), 352-356. 10.1093/gji/ggt251

Terzaghi, K. (1925), Principles of soil mechanics, IV-Settlement and consolidation of clay, Engineering News-Record, 95(3), 874-878.

Vuković, M., and A. Soro (1992), Determination of hydraulic conductivity of porous media from grain-size composition, Water Resources Pubns.

Weller, A., and F. Börner (1996), Measurements of spectral induced polarization for environmental purposes, Environmental Geology, 27(4), 329-334.

Weller, A., and F. D. Boerner (1996), Measurements of spectral induced polarization for environmental purposes, Environmental Geology, 27, 329-334.

Weller, A., and L. Slater (2012), Salinity dependence of complex conductivity of unconsolidated and consolidated materials: Comparisons with electrical double layer models, GEOPHYSICS, 77(5), D185-D198. 10.1190/geo2012-0030.1

Weller, A., L. Slater, and S. Nordsiek (2013), On the relationship between induced polarization and surface conductivity: Implications for petrophysical interpretation of electrical measurements, GEOPHYSICS, 78(5), D315-D325. 10.1190/geo2013-0076.1

Weller, A., L. Slater, S. Nordsiek, and D. Ntarlagiannis (2010), On the estimation of specific surface per unit pore volume from induced polarization: A robust empirical relation fits multiple data sets, Geophysics, 75(4), WA105-WA112.

Weller, A., K. Breede, L. Slater, and S. Nordsiek (2011), Effect of changing water salinity on complex conductivity spectra of sandstones, GEOPHYSICS, 76(5), F315-F327. 10.1190/geo2011-0072.1

Weller, A., L. Slater, A. Binley, S. Nordsiek, and S. Xu (2015a), Permeability prediction based on induced polarization: Insights from measurements on sandstone and unconsolidated samples spanning a wide permeability range, Geophysics, 80(2), D161-D173.

Weller, A., L. Slater, J. A. Huisman, O. Esser, and F.-H. Haegel (2015b), On the specific polarizability of sands and sand-clay mixtures, Geophysics, 80(3), A57-A61.

Zisser, N., A. Kemna, and G. Nover (2010), Dependence of spectral-induced polarization response of sandstone on temperature and its relevance to permeability estimation, Journal of Geophysical Research: Solid Earth, 115(B9), n/a-n/a. 10.1029/2010JB007526 
Zunker, F. (1930), Das Verhalten des Wassers zum Boden [The behavior of groundwater], Zeitschr Pflanzenernäh Düng Bodenkd A, 25.

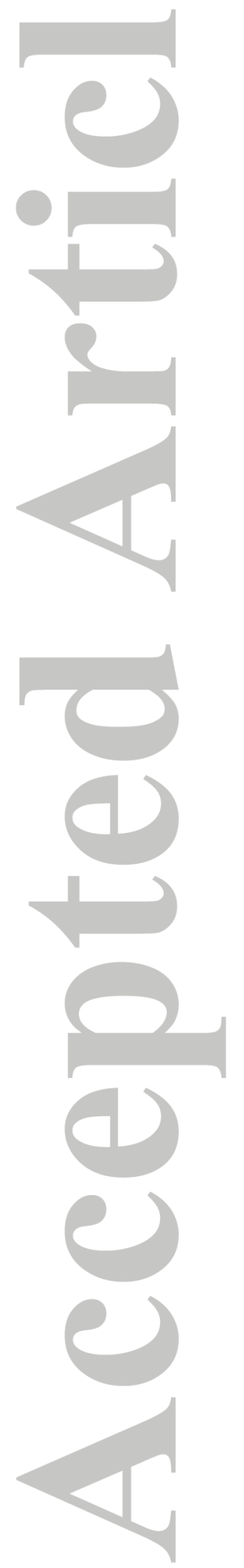




\section{Figures}

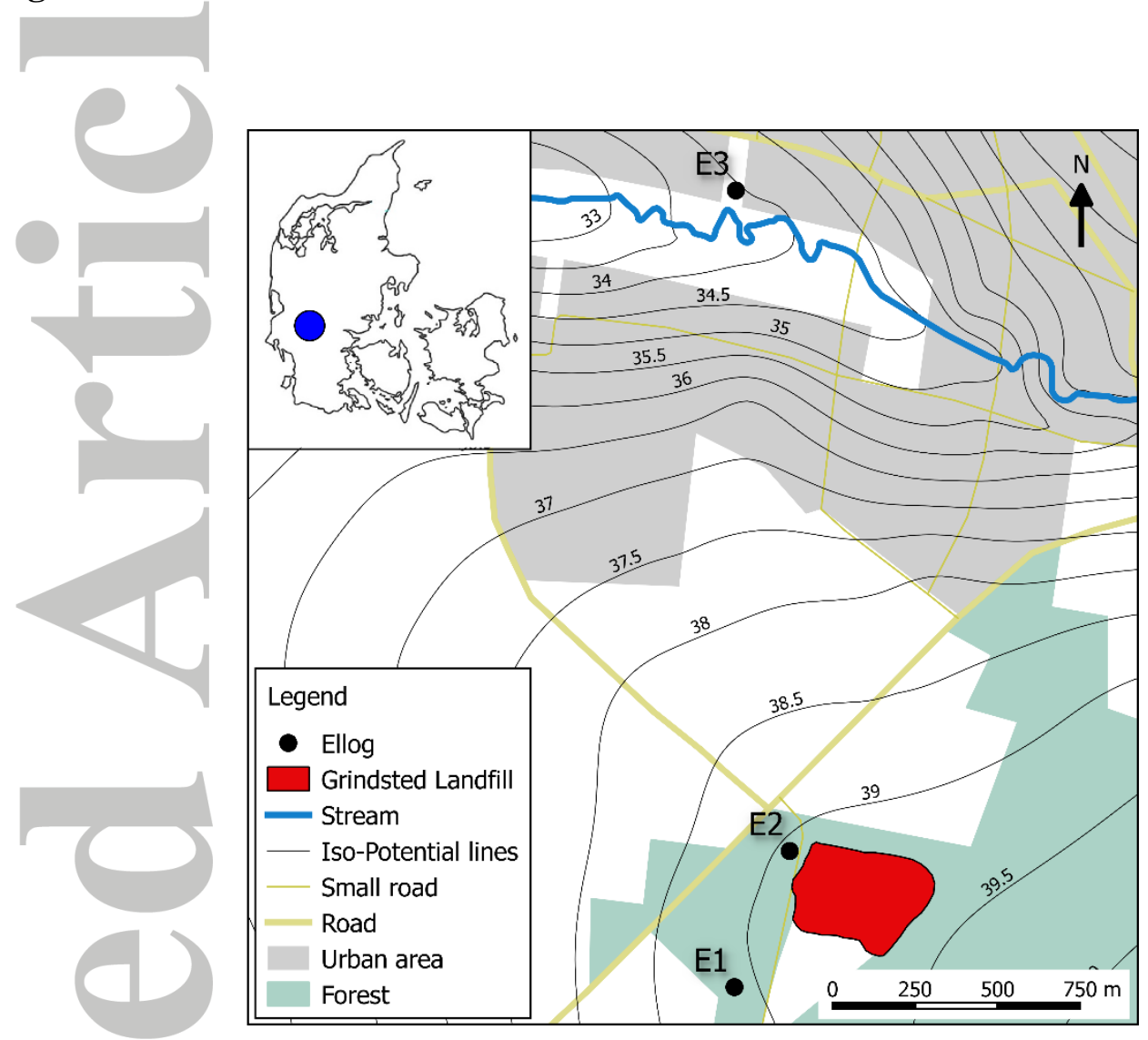

Figure 1. Location of the study area with positions of the El-logs shown with the black dots. The blue dot shows the position of the study site in the map of Denmark.

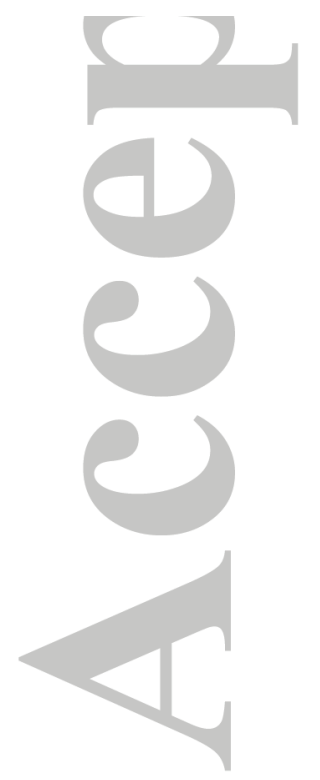




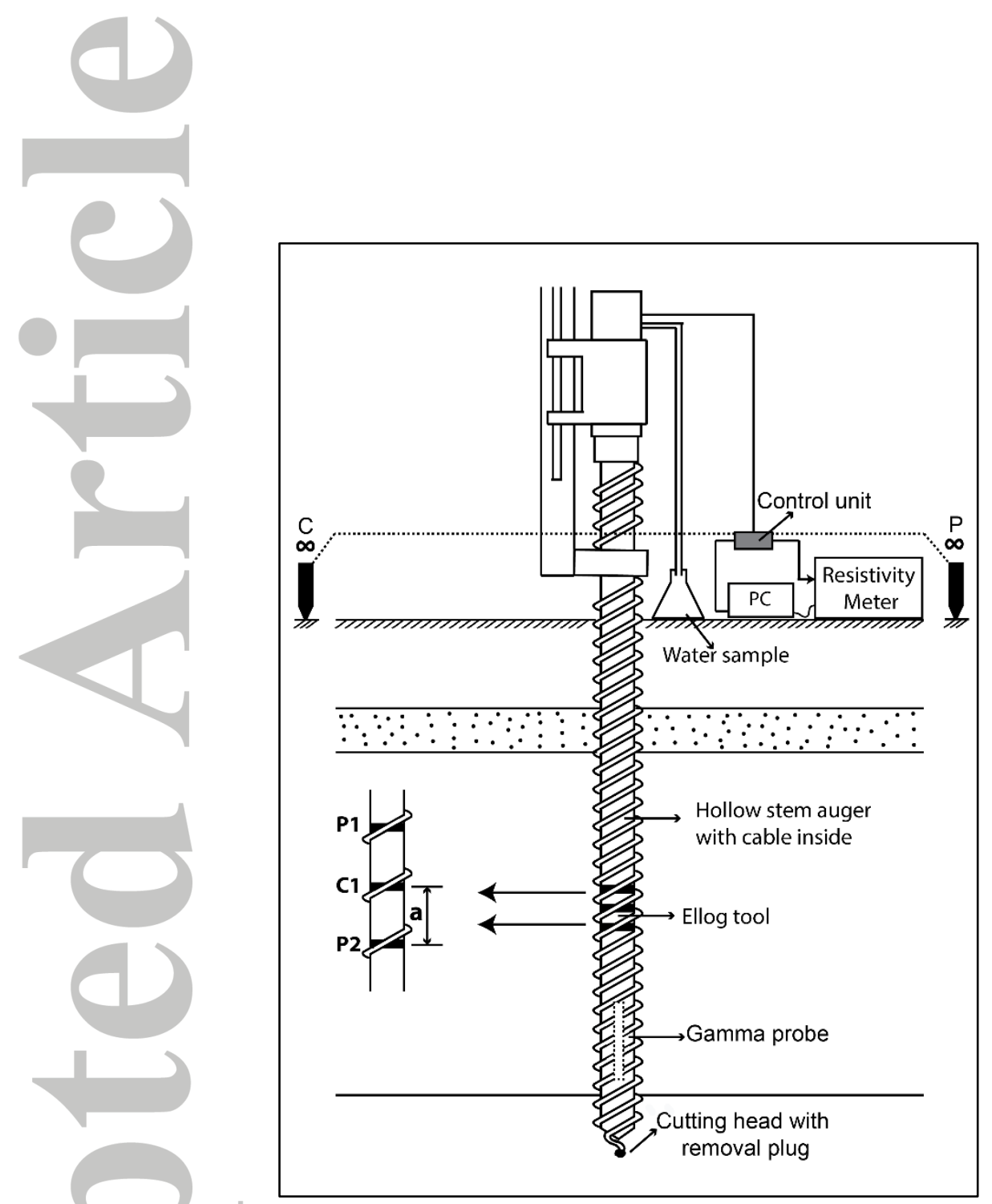

Figure 2. Sketch of principal components of the El$\log$ equipment; $a=20 \mathrm{~cm}$. 

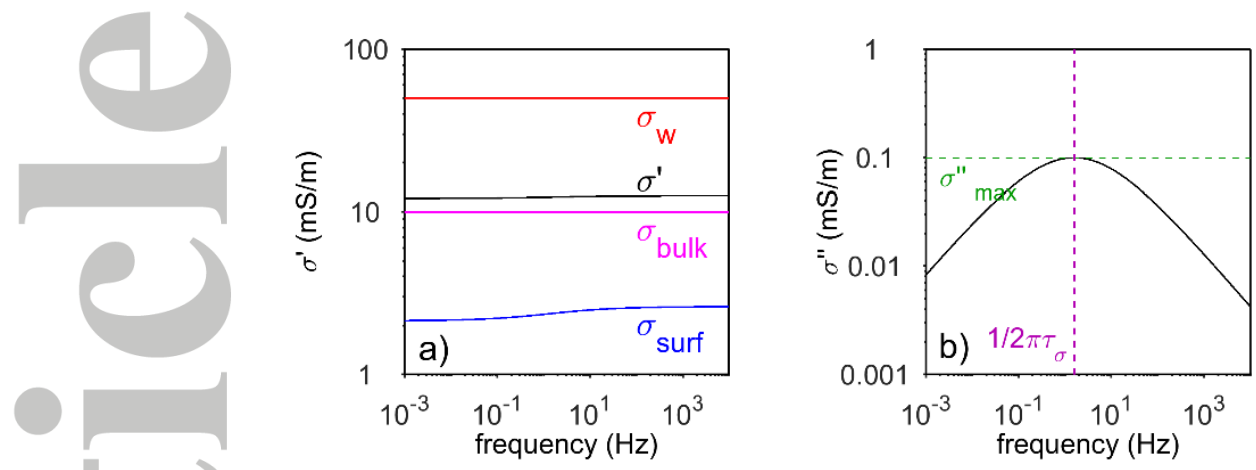

Figure 3. Spectrum of the BIC model computed using $\sigma_{\text {bulk }}=10 \mathrm{mS} / \mathrm{m}, \sigma_{\text {max }}^{\prime \prime}=0.1 \mathrm{mS} / \mathrm{m}, \tau_{\sigma}=$ $0.1 \mathrm{~s}$ and $\mathrm{C}=0.5$. a) real conductivity $\sigma^{\prime}$ (black curve), obtained as the sum of the bulk conductivity $\sigma_{\text {bulk }}$ (magenta curve) and the surface real conductivity $\sigma_{\text {surf }}^{\prime}$. The water conductivity value $\sigma_{\mathrm{w}}$ with formation factor $\mathrm{F}=5$ is also shown. b) imaginary conductivity $\sigma^{\prime \prime}$. Modified from Maurya et al. [2018].

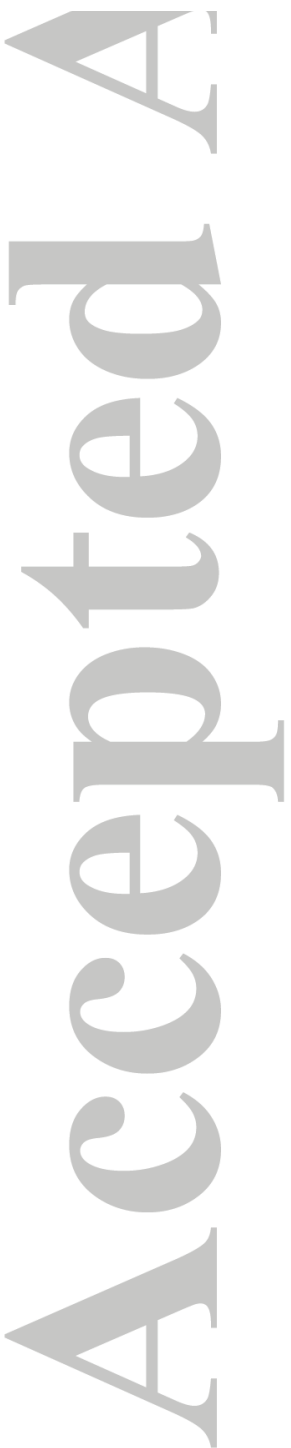



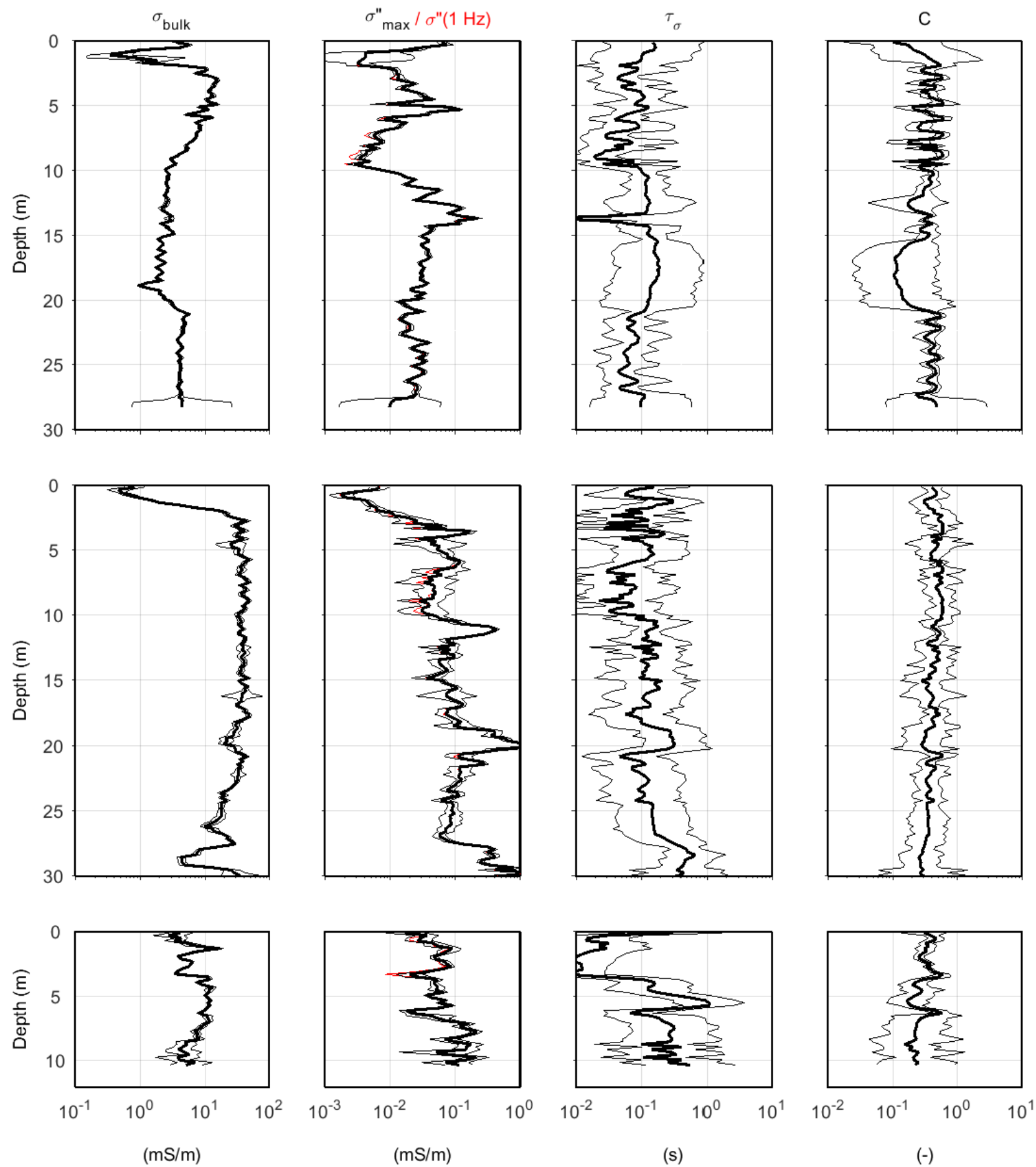

(s)

$(-)$

Figure 4. Invêrsion models for El-log E1 (top), E2 (middle) and E3 (bottom). All four inversion parameters are shown in the four figure columns (thick black lines), together with the confidence interval defined through equation (17) (thin black lines). In the second column, the imaginary conductivity $\sigma^{\prime \prime}(f=1 \mathrm{~Hz})$, computed from the parameters $\left\{\sigma_{\max }^{\prime \prime}, \tau_{\sigma}, C\right\}$, is shown in red (but $\sigma^{\prime \prime}(f=1 \mathrm{~Hz})$ is visible only where it differs significantly from $\left.\sigma_{\max }^{\prime \prime}\right)$. 


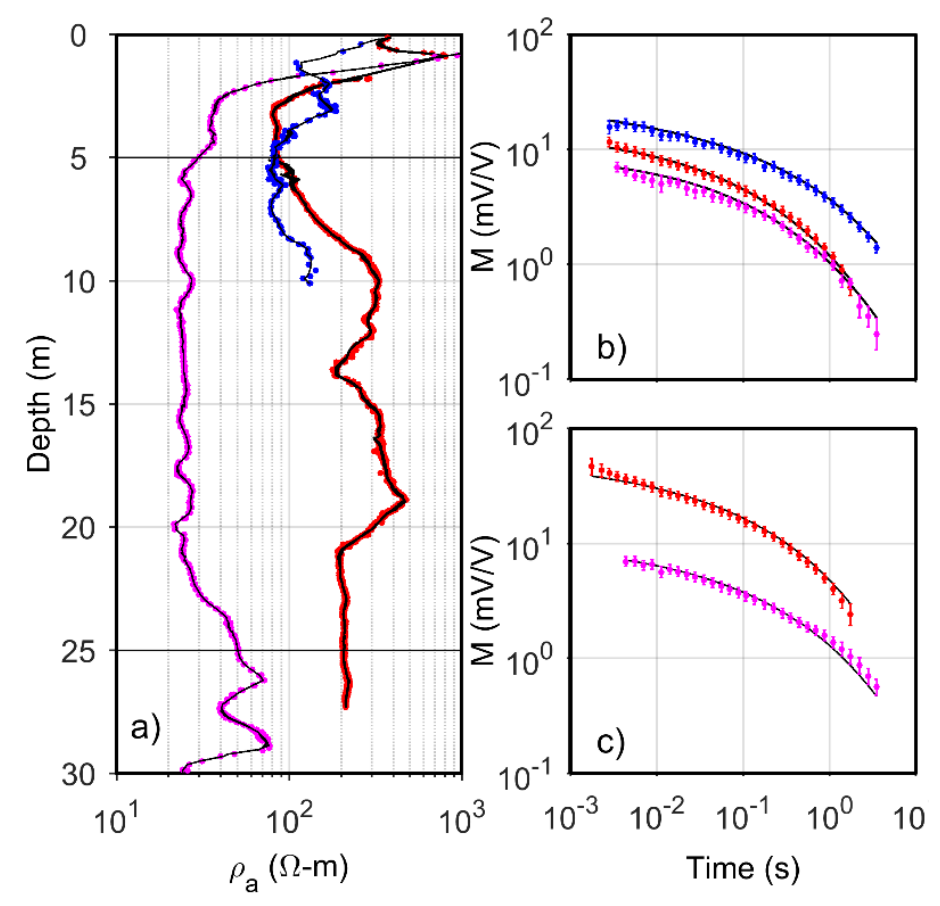

Figure 5. Data for the three El-logs (red markers: E1; magenta markers: E2; blue markers: E3) and corresponding data fits (black lines). a) Apparent resistivity data and fit. b) IP decays and fit with current electrode C1 (see Figure 2) at depth=5 m. c) IP decays and fit with current electrode C1 at depth $=25 \mathrm{~m}$. 


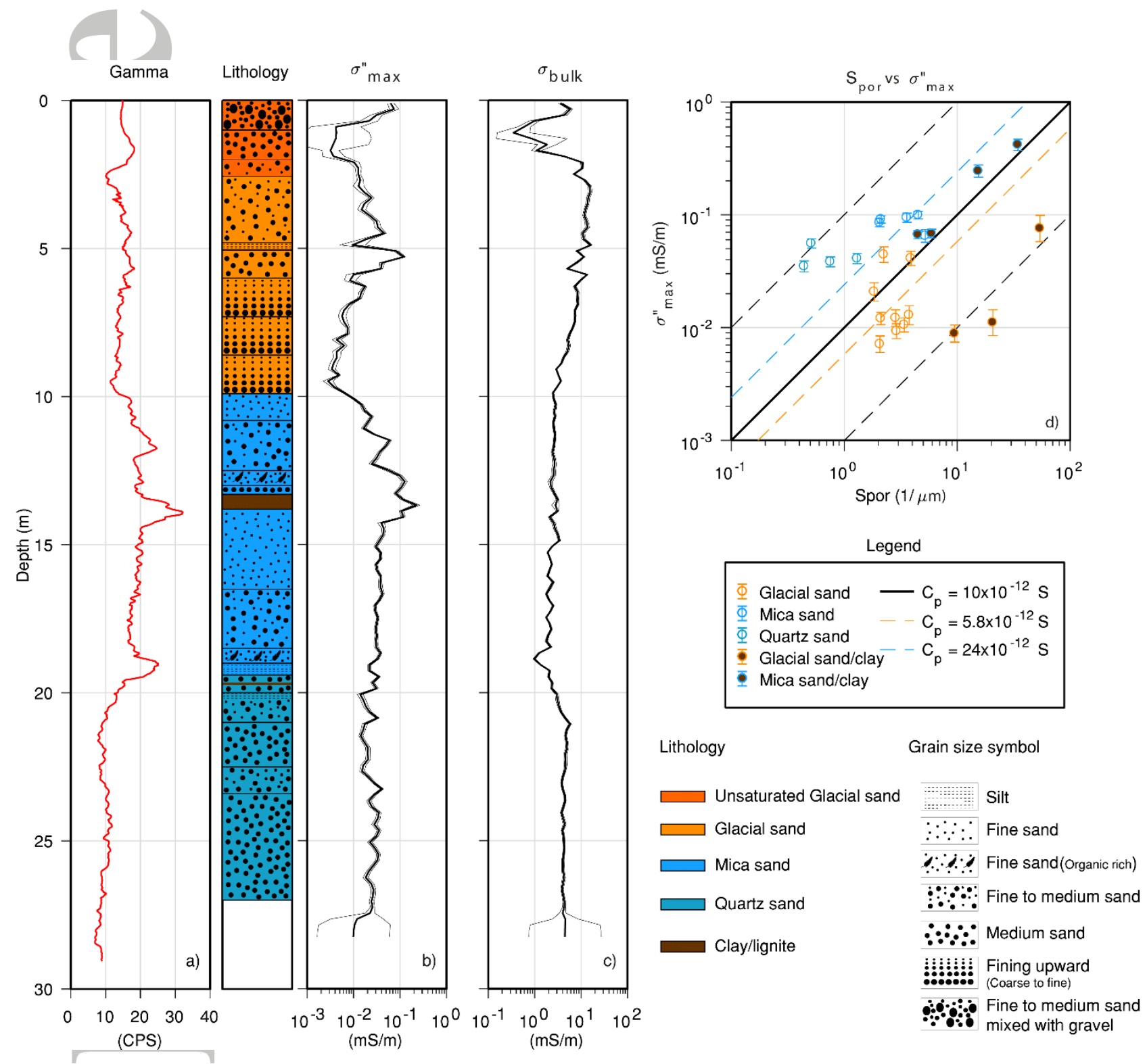

Figure 6. a) Gamma log measured in El-log-E1 and corresponding lithological log from Sc1, b) maximum imaginary conductivity, $\boldsymbol{\sigma}^{\prime \prime}{ }_{\max }$ c) Bulk conductivity $\boldsymbol{\sigma}_{\text {bulk }}$. The thin lines, left and right side of both parameters represent the lower and upper error bounds estimated from equation (17) d) Correlation between imaginary conductivity $\left(\boldsymbol{\sigma}^{\prime \prime}{ }_{\text {max }}\right)$, corrected for water conductivity, and $\boldsymbol{S}_{\text {por }}$ measured in E1. The thin dashed black line shows the deviation of one order of magnitude from the $\boldsymbol{C}_{\boldsymbol{p}}=10 \times 10^{-12} \mathrm{~S}$ line.

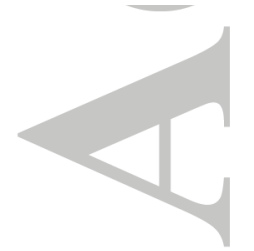




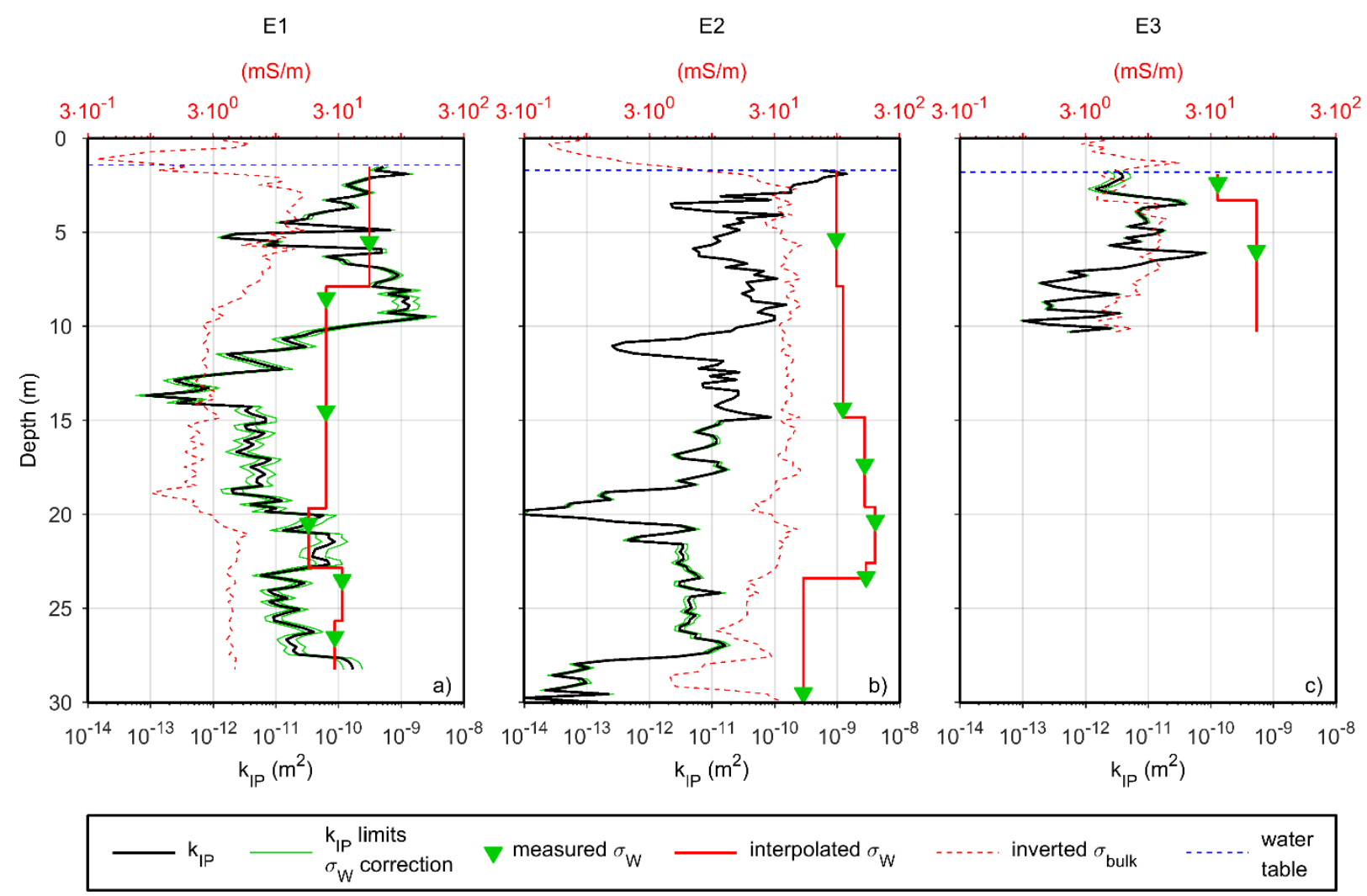

Figure 7. Effect of water conductivity $\sigma_{W}$ on permeability estimation for: a) El-log E1; b) El-log E2; c) El-log E3. Green triangles: $\sigma_{W}$ measured in screens. Continuous red lines: interpolated $\sigma_{W}$ depth-logs. Dashed red lines: $\sigma_{\text {bulk }}$ retrieved from the BIC inversions. Black lines: permeability $k_{I P}$. Green lines: $k_{I P}$ limits due to the correction for water conductivity (equation 16). Dashed blue lines: water table levels. 


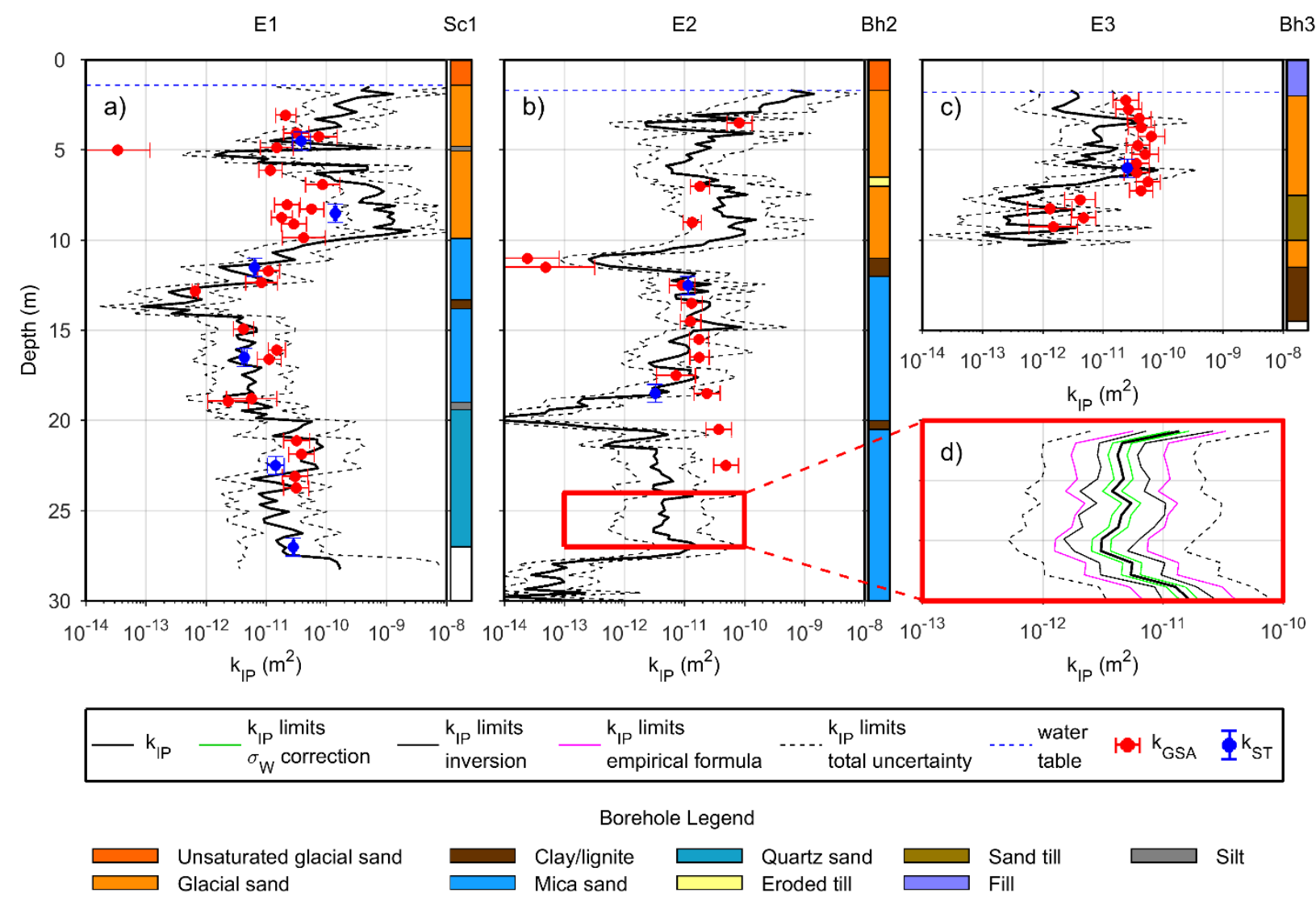

Figure 8. Vertical Permeability $k_{I P} \operatorname{logs}$, estimated using equation (9) and (13), in: a) El-log E1; b) El-log E2; c) El-log E3. d) zoom-in of El-log E2. Thick continuous black lines: $k_{I P}$ estimation. Green lines: $k_{I P}$ limits due to the correction for water conductivity (equation 16). Thin black lines: $k_{I P}$ limits due to the inversion uncertainty (equation 19). Magenta lines: $k_{I P}$ limits due to the uncertainty on the petrophysical empirical formula (equation 15). Dashed black lines: $k_{I P}$ limits due to the total uncertainty (equation 20). Dashed blue lines: water table levels. The horizontal error bars show the estimated uncertainty in grain size estimated $\mathrm{k}$. The vertical error bar in slug-test estimates shows top and bottom of the screen used for measurements. In Sc1 the permeability of a GSA sample around $13.8 \mathrm{~m}$ is $4.70 \times 10^{-17}$ and is not shown in the plot. 

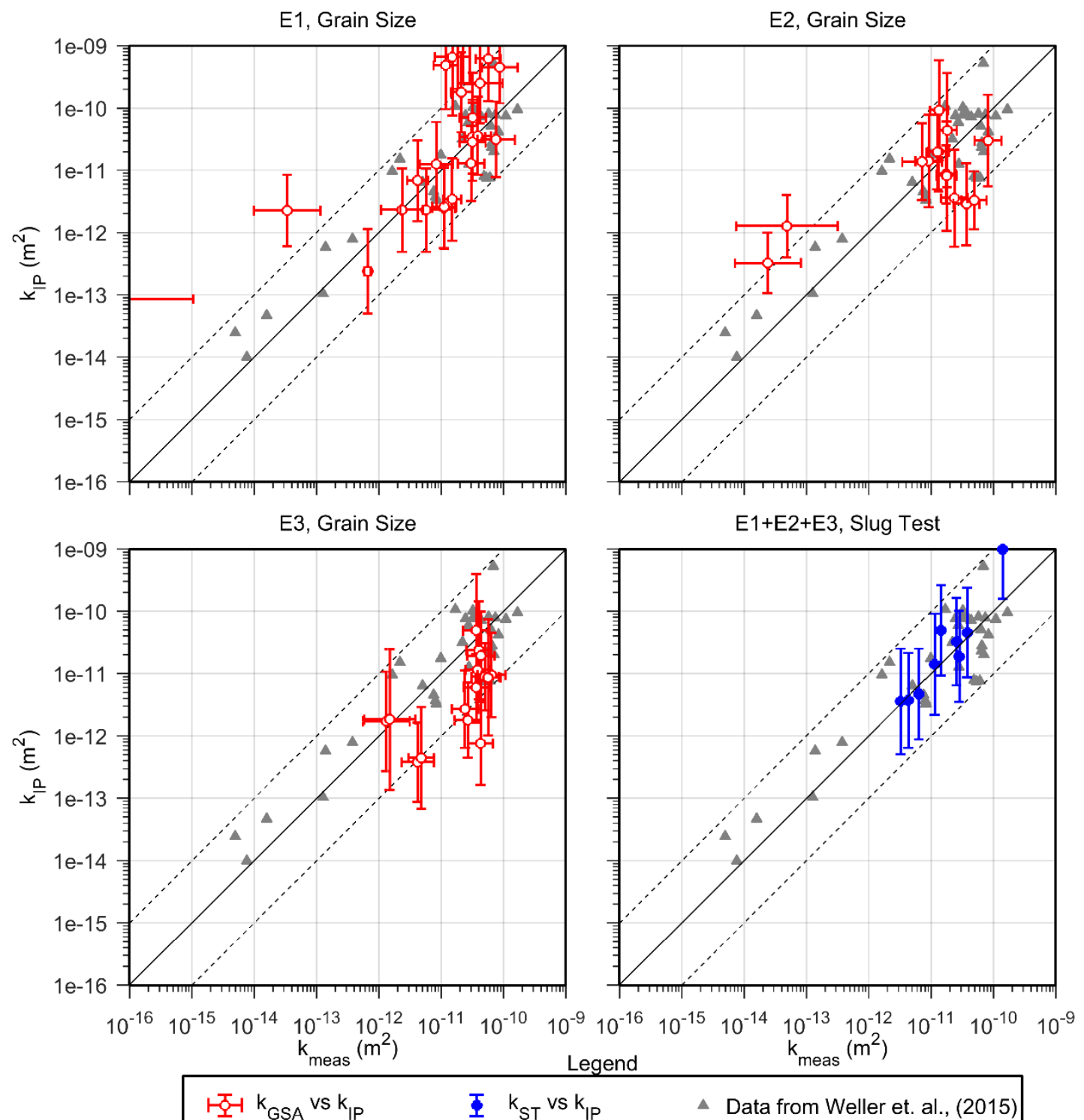

Figure 9. Cross plots between measured $k$ ( $\left.\boldsymbol{k}_{\text {meas }}\right)$, (from grain size analyses and slug tests, Bh1-3, and Sc1) and IP derived $\mathrm{k}\left(\boldsymbol{k}_{\boldsymbol{I P}}\right)$ for El-logs E1, E2 and E3 using equations (9) and (13). Dashed lines show deviation of one order of magnitude. 